\title{
Experimental and computational studies of fatty acid distribution networks
}

\author{
Yong Liu abc, Germán Buendía-Rodríguez ${ }^{\mathrm{d}}$, Claudia Giovanna Peñuelas-Rívas a, \\ Zhiliang Tan ${ }^{\mathrm{b}}$, María Rívas-Guevara ${ }^{\mathrm{e}}$, Esvieta Tenorio-Borroto a , Cristian R. \\ Munteanu ${ }^{\mathrm{c}}$, Alejandro Pazos ${ }^{\mathrm{c}}$ and Humberto González-Díaz ${ }^{\mathrm{fg}}$ \\ ${ }^{a}$ Faculty of Veterinary Medicine and Animal Science, Autonomous University of the State of Mexico, Toluca, 50090, \\ Mexico \\ ${ }^{b}$ Key Laboratory of Subtropical Agro-ecological Engineering, Institute of Subtropical Agriculture, the Chinese \\ Academy of Sciences, Changsha, Hunan 410125, P. R. China \\ ${ }^{c}$ Computer Science Faculty, University of A Coruna, Campus de Elviña s/n, A Coruña, 15071, Spain. E-mail: \\ crm.publish@gmail.com; Fax: +34981 167 160; Tel: +34 981167000 \\ ${ }^{d}$ National Center for Disciplinary Research on Animal Physiology and Breeding, National Institute of Forestry, \\ Agriculture and Livestock Research, Queretaro, 76280, Mexico. E-mail: gerarticulos@hotmail.com; Fax: +52 419 \\ 292 0033; Tel: +52 4192920036 \\ ${ }^{e}$ Ethnobiology and Biodiversity Research Center, Chapingo Autonomous University, Texcoco, 56230, Mexico \\ ${ }^{f}$ Department of Organic Chemistry II, Faculty of Science and Technology, University of the Basque Country \\ UPV/EHU, Leioa, 48940, Spain \\ ${ }^{g}$ IKERBASQUE, Basque Foundation for Science, Bilbao, 48011, Spain
}

\begin{abstract}
Unbalanced uptake of Omega 6/Omega $3(\omega-6 / \omega-3)$ ratios could increase chronic disease occurrences, such as inflammation, atherosclerosis, or tumor proliferation, and methylation methods for measuring the ruminal microbiome fatty acid (FA) composition/distribution play a vital role in discovering the contribution of food components to ruminant products (e.g., meat and milk) when pursuing a healthy diet. Hansch's models based on Linear Free Energy Relationships (LFERs) using physicochemical parameters, such as partition coefficients, molar refractivity, and polarizability, as input variables $\left(\mathrm{V}_{\mathrm{k}}\right)$ are advocated. In this work, a new combined experimental and theoretical strategy was proposed to study the effect of $\omega-6 / \omega-3$ ratios, FA chemical structure, and other factors over FA distribution networks in the ruminal microbiome. In step 1, experiments were carried out to measure long chain fatty acid (LCFA) profiles in the rumen microbiome (bacterial and protozoan), and volatile fatty acids (VFAs) in fermentation media. In step 2, the proportions and physicochemical parameter values of LCFAs and VFAs were calculated under different boundary conditions $\left(\mathrm{c}_{\mathrm{j}}\right)$ like $\mathrm{c}_{1}=$ acid and/or base methylation treatments, $\mathrm{c}_{2}=$ with/without fermentation, $c_{3}=$ FA distribution phase (media, bacterial, or protozoan microbiome), etc. In step 3, Perturbation Theory (PT) and LFER ideas were combined to develop a PT-LFER model of a FA distribution network using physicochemical parameters $\left(\mathrm{V}_{\mathrm{k}}\right)$, the corresponding Box-Jenkins $\left(\Delta \mathrm{V}_{\mathrm{kj}}\right)$ and PT operators $\left(\Delta \Delta \mathrm{V}_{\mathrm{kj}}\right)$ in statistical analysis. The best PT-LFER model found predicted the effects of perturbations over the FA distribution network with sensitivity, specificity, and accuracy > 80\% for 407655 cases in training + external validation series. In step 4, alternative PT-LFER and PT-NLFER models were tested for training Linear and Non-Linear Artificial Neural Networks (ANNs). PT-NLFER models based on ANNs presented better performance but are more complicated than the PT-LFER model. Last, in step 5, the PT-LFER model based on LDA was used to reconstruct the complex networks of perturbations in the FA distribution and compared the giant components of the observed and predicted networks with random Erdős-Rényi network models. In short, our new PT-LFER model is a useful tool for predicting a distribution network in terms of specific fatty acid distribution.
\end{abstract}




\section{Introduction}

The $\omega-6 / \omega-3$ ratio plays an important role not only in the pathogenesis of cardiovascular diseases, but also in cancer, inflammatory and autoimmune diseases. ${ }^{1-3} \mathrm{~A}$ high $\omega-6 / \omega-3$ ratio is considered detrimental for human health, a value close to 1 is considered protective against the degenerative pathologies. ${ }^{4}$ The inconsistent results ${ }^{5-8}$ combined with meta-analysis methods reported the contributions of $\omega$-3 fatty acids to cardio- and cerebrovascular diseases, inflammation, or tumor proliferation. Some researchers tend to explain the metabolism mechanism not only in terms of absolute amounts of $\omega-6$ and $\omega-3$, but also their balance.

Enrichment of ruminant meat or milk with $\omega-3$ PUFAs, further to decrease $\omega-6 / \omega-3$ uptake ratios, is an efficient method to introduce these beneficial PUFAs into diet, but the biohydrogenation process of ruminal complexes limits their bioavailability. ${ }^{9}$ Petit et al. reported adding whole linseeds rich in ALA to the ratios of dairy cows, which resulted in the lowest $\omega-6 / \omega-3$ ratio in milk compared to micronized soybeans or sunflower seeds. ${ }^{10}$ Hess et al. ${ }^{11}$ proved that the incorporation of $\omega-3$ PUFAs into animal blood and muscle depends directly on the dietary supply of specific fatty acid. In addition, the long chain fatty acids (LCFAs) have to be methylated by acid- and/or base-methylation before determining it using a gas chromatograph (GC). There are different methylation methods for measuring LCFAs of milk, muscle or ruminal microbial membranes, ${ }^{12-14}$ accompanied by generating different results. The structure properties of LCFAs (especially the number, location or topology structure of double bonds) are highly related to the chronic disease. To address this problem, it was postulated that the LCFAs in ruminal microbial membranes change with the supply of $\omega-6 / \omega-3$ ratios. This work is aimed to look for a new classification model by means of Chemoinformatics, combined with an original experimental fatty acid distribution in ruminal microbial membranes.

On the other hand, Chemoinformatics is related to Machine Learning, Chemometrics and Bioinformatics, ${ }^{15}$ and it combines the scientific working fields of Chemistry, Information Science, and the areas of topology, chemical graph theory, and data mining in the chemical space. Corwin Hansch was one of the founders of modern Chemoinformatics, which is based on the lipophilicity-activity relationship. A type of Hansch model is as follows: ${ }^{16}$

$$
f\left(\varepsilon_{i}\right)=a_{0}+a_{1} \cdot \log P_{i}+a_{2} \cdot p K_{a}+a_{3} \cdot M R-a_{4} \cdot\left(\log P_{i}\right)^{2}
$$

It is well known that steric, electrostatic, and hydrophobicity factors may be biologically relevant. ${ }^{17,18}$ In this equation, the different parameters can be used as inputs to account for the factors: such as water/noctanol partition coefficients $\left(\mathrm{P}_{\mathrm{i}}\right)$, molecular refractivity $(\mathrm{MR})$, logarithmic acidity constants $\left(\mathrm{pK}_{\mathrm{a}}\right)$, and other physicochemical parameters to quantify different global molecular properties. ${ }^{19}$ The outputs of the model are the values of a molecular property $\left(\varepsilon_{\mathrm{i}}\right)$ or a function of this property $\mathrm{f}\left(\varepsilon_{\mathrm{i}}\right)$ for a given chemical compound or molecular entity $\left(\mathrm{m}_{\mathrm{i}}\right)$. The innovations of these models are described as follows. (1) The use of the linear regression to seek multivariate linear equations is able to predict the values of $\mathrm{f}\left(\varepsilon_{\mathrm{i}}\right)$, employing several input variables. (2) Hansch also generalized the use of lipophilicity parameters by the formulation of parabolic models for non-linear relationships. (3) The logarithmic terms $\left(\log \mathrm{P}_{\mathrm{i}}\right)$ of $\mathrm{P}_{\mathrm{i}}$ are commonly used as the measures of molecular lipophilicity and play an important role in the model. In turn, $\log \mathrm{P}_{\mathrm{i}}$ values can be predicted either by atomic methods (like $\mathrm{X} \log \mathrm{P}$ or $\mathrm{A} \log \mathrm{P}$ ) or by chemical fragment methods (like $\mathrm{C} \log \mathrm{P}_{\mathrm{i}}$ or similar methods). ${ }^{20,21}$ From a physical-chemistry point of view, Hansch's model is an extra-thermodynamic approach closely related to Linear Free Energy Relationships (LFERs). ${ }^{22,23}$ The designation of Hansch's models as LFER equations comes from the use of parameters depending on Gibbs free energy $\left(\mathrm{G}_{\mathrm{i}}\right)$ of the ith process. ${ }^{24}$ The changes in the values of this potential during a process obey a logarithmic statistical thermodynamic relationship with equilibrium constant $\mathrm{K}_{\mathrm{i}}{ }^{25}$

$$
\Delta \mathrm{G}_{\mathrm{i}}=-\mathrm{RT} \log \left(\mathrm{K}_{\mathrm{i}}\right)
$$

However, in these types of equations, other physicochemical parameters or molecular descriptors can also be used to quantify the effect of changes on the chemical structure over a characteristic of interest. It means that molecular descriptors for a given molecule can be used, which are not only thermodynamic constants, but also other theoretical measures of molecular lipophilicity, electronegativity, polarizability, or molecular topology properties, ${ }^{19}$ etc. The values of these input variables $\left({ }^{\mathrm{i}} \mathrm{V}_{\mathrm{k}}\right)$ may be calculated as physicochemical parameters or molecular descriptors of different types $(k)$ for a given molecule $\left(\mathrm{m}_{\mathrm{i}}\right)$. In fact, the notation can be extended including extra-thermodynamic functions or parameters as follows. 


$$
f\left(\varepsilon_{i}\right)=\sum_{j=1}^{j_{\max }} a_{k} \cdot V_{k}+\sum_{j=1}^{j_{\max }} b_{j} \cdot\left({ }^{i} V_{k}\right)^{2}+e_{0}
$$

Overall, the basic assumption of Hansch's analysis is that similar molecules have similar activities. ${ }^{26-}$ ${ }^{28}$ This principle is also called the Structure-Activity Relationship (SAR). The SAR paradox refers to the fact that not in all cases similar molecules have similar activities. The underlying problem is therefore how to define a small difference at a molecular level. The problem is relevant since each kind of property, e.g., solubility, reactivity, or metabolism, is expected to depend on another difference. It means that "small" variations or perturbations need to be quantified at the molecular structural level, which in turn implies a "small" linear change in the free energy of interaction of a drug with a receptor.

In our opinion, the ideas of the Perturbation Theory (PT) $)^{29}$ can be used to account for this problem in the context of Chemoinformatics. That is why in this work PT and LFER ideas were used to formulate a new PT-LFER approach. This PT-LFER approach is a generalization of the classic Hansch ExtraThermodynamics method for Chemoinformatics. The proof-of-concept was also demonstrated by an experimental-theoretical study on complex networks of FA distribution in Lipidomics. To this end, first the experiments were carried out to determine LCFA composition in the ruminal microbiome. Next, the Chemoinformatics study was included, starting with the definition, training, and validation of new PTLFER classification models. Machine Learning methods such as Artificial Neural Networks (ANNs) were used to test PT-NLFER models (non-linear analogues of PT-LFER). Next, the best PT-LFER model found was used to predict the effect of perturbations on initial boundary conditions over a large complex network of FA distribution/uptake in the ruminal microbiome. The observed complex network for the data reported was constructed and compared for the first time with the predicted network and model random networks of similar size. Last, the theoretical section was completed with a comparative study of the PT-LFER classification model found using other non-linear models. This study was of major relevance due to previous results that point to a strong relationship between $\omega-6 / \omega-3$ ratios of FA intake and human health. ${ }^{30,31}$ Accordingly, this work paves the way for evaluating the effect of perturbations on complex molecular systems involved in chemical structures and boundary experimental conditions.

\section{Materials and methods}

\subsection{Experimental section}

In the workflow of this experimental part (Fig. 1), the general details of the experimental procedures used in experiment 1 and experiment 2 are explained as follows.

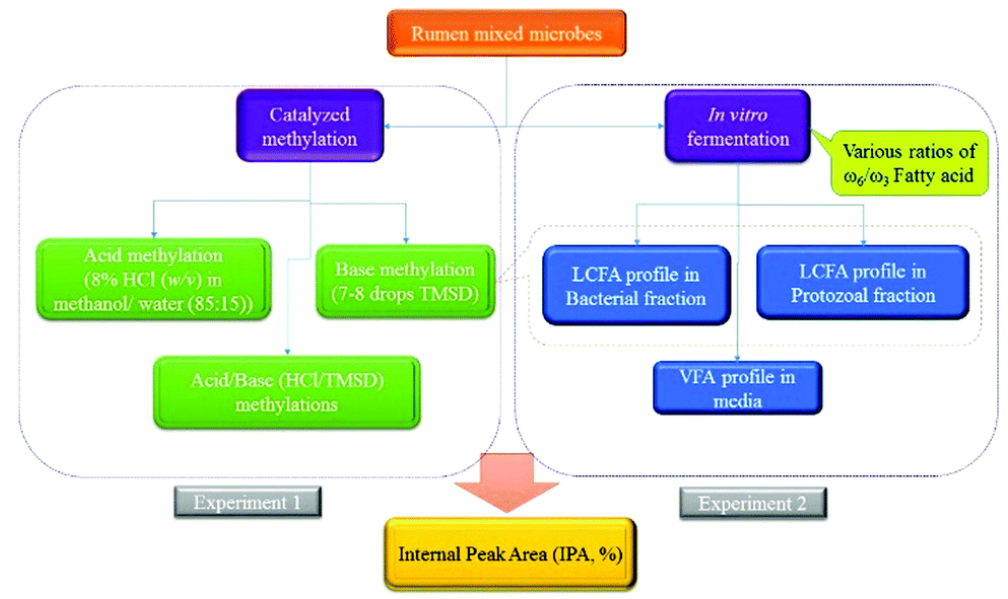

Fig. 1 Workflow of the experimental section (dataset): IPA values of each FA based on bacterial membrane FAs catalyzed by methylation methods (experiment 1) and IPA values obtained from bacterial, protozoan, and media fractions by the fermentation of various exogenous $\omega-6 / \omega-3$ ratio supplementation by base methylation (experiment 2 ). 


\subsubsection{Animal welfare.}

Three adult male Pelibuey sheep with permanent rumen-fistula (body weight, $45.0 \pm 5.0 \mathrm{~kg}$ ) were used as an inoculum donor according to the Mexican Official Standard (NOM-220-SSA1-2002). Nutritional composition of fodder for animal donors was according to the National Research Council (NRC). ${ }^{32}$ All the animal procedures and protocols were approved by the Animal Care Committee, National Center for Disciplinary Research in Animal Breeding and Physiology (CENID FyMA), and National Institute of Forestry, Agriculture and Livestock (INIFAP), Queretaro, Mexico.

\subsubsection{Details of in vitro fermentation.}

The in vitro details are according to the description of Tang et al. ${ }^{33}$ with the particle-free rumen fluid mixed with the artificial saliva buffer solution ${ }^{34}$ in a proportion of $1: 2(\mathrm{v} / \mathrm{v})$ at $39{ }^{\circ} \mathrm{C}$ under continuous flushing of $\mathrm{CO}_{2}$. Microbial fatty acids were prepared according to the method developed by Or-Rashid. ${ }^{14}$ More specifically, the microbial and protozoan samples were separated by differential centrifugation according to the method described by Legay-Carmier and Bauchart. ${ }^{35}$

\subsubsection{Specific procedures of experiment 1.}

Ruminal mixed microbes without fermentation were catalyzed by acid methylation $(8 \% \mathrm{HCl}(\mathrm{w} / \mathrm{v})$ dissolved in methanol/water $(85 / 15))$, ${ }^{12}$ base methylation (trimethylsilyldiazomethane, TMSD) ${ }^{14}$ combined acid- and base-methylations (first catalyzed with $8 \% \mathrm{HCl}$, and subsequently catalyzed with TMSD), respectively. The values of Peak Area, $\mathrm{PA}_{(\mathrm{i})}$, for each LCFA under different sets of experimental conditions $c_{j}$ (different samples) were determined by GC ${ }^{14,36}$ (Model 6890N, Agilent Technologies Inc., USA) using a HP-88 Column at laboratory of CENID FyMA, INIFAP, and VFAs were determined using a DB-FFAP column. The values of peak area obtained were used to calculate the internal peak area, $\operatorname{IPA}(\%)$, as follows.

$$
\operatorname{IPA}(\%)_{i j}=100 \cdot\left(\frac{\mathrm{PA}_{(i)}}{\sum_{m_{i} c c_{j}}^{n_{j}} \mathrm{PA}_{(i)}}\right)
$$

\subsubsection{Specific procedures of experiment 2.}

This study was conducted to evaluate the effect of various exogenous $\omega-6 / \omega-3$ ratios on the biohydrogenation metabolism of the microbial microbiome. The $\omega-6$ and $\omega-3$ PUFAs, linoleic acid (LA, L1376-5g, Sigma-Aldrich) and $\alpha$-linolenic acid (ALA, L2376-500 mg, Sigma-Aldrich) with a total amount of $100 \mathrm{mg} \mathrm{g}^{-1}$ in substrates were set at the ratios of $100: 0,90: 10,80: 20,66: 33,50: 50$ and $20: 80$, respectively.

Food components used to feed the animals were the same as those used in experiment 1 . All fermentation lipid samples extracted with a chloroform-methanol mixture $(2: 1, \mathrm{v} / \mathrm{v})^{37}$ from bacterial and protozoan fractions were catalyzed by base methylation (TMSD, herein). ${ }^{14}$ LCFA profiles extracted from bacterial and protozoan fractions and the VFA profiles were determined to calculate IPA(\%), and the concentration (mM) of VFA profiles was also calculated.

\subsection{Theoretical section}

\subsubsection{Workflow used for the PT-LFER}

Chemoinformatics study. In the second section, a Chemoinformatics study of the results obtained in the Experimental section was carried out. Fig. 2 shows the workflow diagram that states the integration of both (experimental and theoretical) sections. For the analysis, the chromatographic data about IPA(\%) values of fatty acids were collected under different $\omega-6 / \omega-3$ ratios and experimental conditions $c_{j}$. Next, we defined the PT-LFER model. After that, we calculated the values of input variables, including molecular descriptors $\left({ }^{\mathrm{i}} \mathrm{V}_{\mathrm{k}}\right)$ of class $\mathrm{k}$ for every ith fatty acid molecule, and perturbation operators $\Delta \Delta \mathrm{V}_{\mathrm{k}}\left(\mathrm{c}_{\mathrm{j}}\right)$. After that we performed the statistical analysis and obtained the PT-LFER model. More details are explained in some steps as follows. 


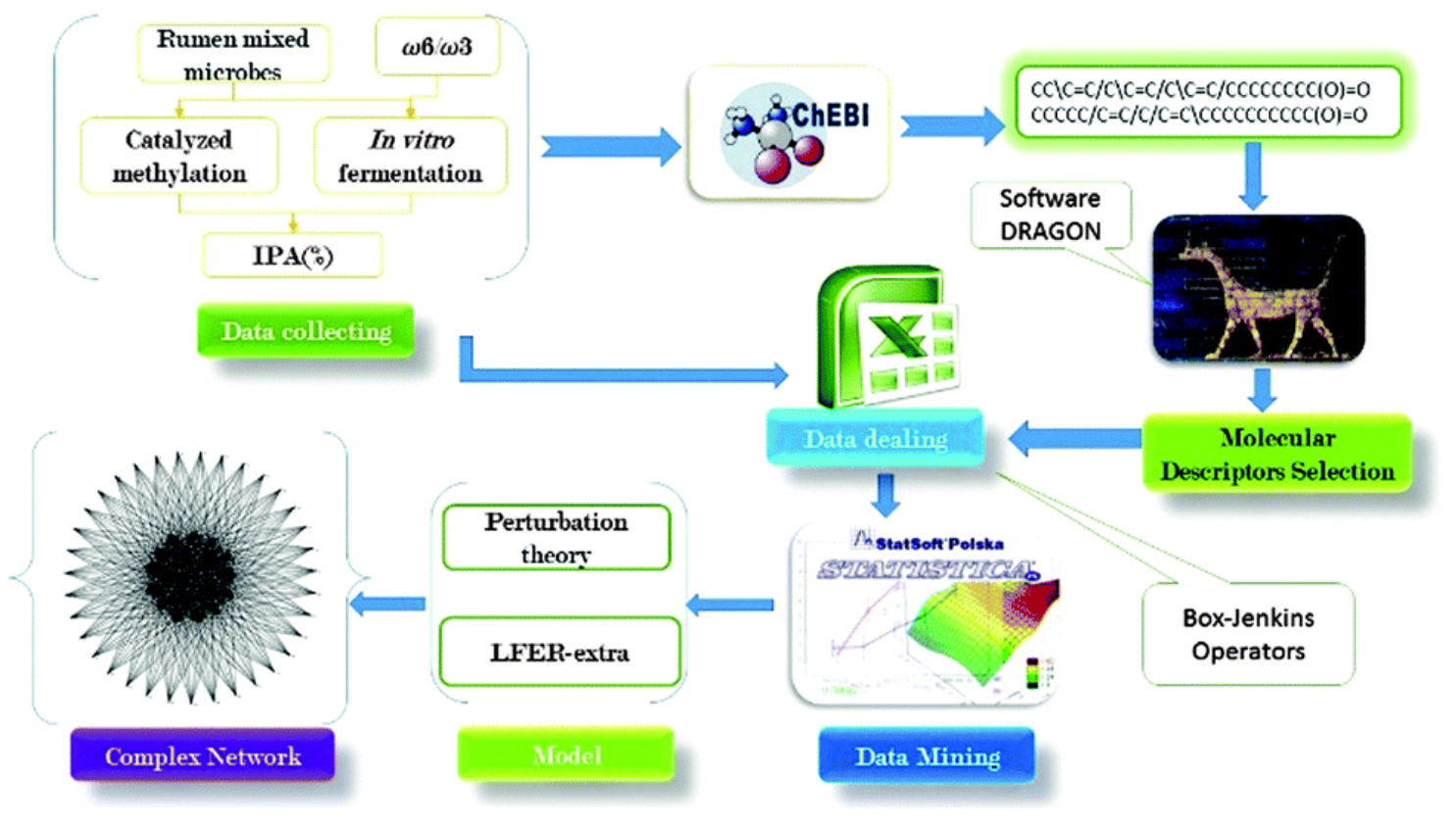

Fig. 2 Workflow used herein to seek PT-LFER models.

\subsubsection{Theoretical details of the PT-LFER models.}

In a recent study, Gonzalez-Díaz et al. ${ }^{29}$ has formulated a general-purpose PT model for multipleboundary Chemoinformatics problems. In this work, this theory is extended to the study of PT-LFER models of perturbations in complex networks. Let a general function $f\left(\mathrm{~L}_{n r}\right)$ be useful to quantify the occurrence $\left(\mathrm{L}_{\mathrm{nr}}=1\right)$ or not $\left(\mathrm{L}_{\mathrm{nr}}=0\right)$ of a process involving a set of molecules $\left(\mathrm{m}_{\mathrm{i}}\right)$ in a complex system. It is considered that all the possible states form a network of states. The network nodes are the initial or reference states ( $r$ ) linked to their respective final or new states (n) reached by the system after a perturbation of the initial conditions. It separates into a set of multiple initial experimental boundary conditions ${ }^{\text {ref }} c_{j} \equiv\left(c_{0}, c_{1}, c_{2}, c_{3}, \ldots, c_{n}\right)$ (conditions of reference) and a different or new set of boundary conditions ${ }^{\text {new }} c_{j} \equiv\left(c_{0}, c_{1}, c_{2}, c_{3}, \ldots, c_{n}\right)$ (conditions of new) after one or multiple perturbations (changes in these conditions). The PT-LFER model proposed herein is a linear equation with the following form:

$$
{ }^{\prime} f\left(L_{\mathrm{nr}}\right)_{\mathrm{new}}=a_{0}+a_{1} \cdot f\left(\varepsilon_{i j}\right)_{\mathrm{ref}}+a_{2} \cdot\left\langle f\left(\varepsilon_{i j}\right)\right\rangle_{\mathrm{ref}}+\sum_{j=1, k=1}^{j=j_{\max }, k=k_{\max }} a_{k j} \cdot \Delta \Delta V_{k}\left(c_{j}\right)
$$

The output function ' $\mathrm{f}\left(\mathrm{L}_{\mathrm{nr}}\right)_{\text {new }}$ is a score used in Linear Discriminant Analysis (LDA) to calculate the outputs or posteriori probability of binary classification of inputs $L_{n r}=1$ or $L_{n r}=0 .{ }^{38}$ The vectors $v_{i}=$ $\left[\mathrm{f}\left(\varepsilon_{\mathrm{ij}}\right)_{\text {ref }}, \quad\left\langle\mathrm{f}\left(\varepsilon_{\mathrm{ij}}\right)\right\rangle_{\text {ref }}, \quad \omega-3, \quad \omega-6, \quad{ }^{\mathrm{i}} \mathrm{V}_{1}, \ldots,{ }^{\mathrm{i}} \mathrm{V}_{\mathrm{kmax}}, \quad \Delta \mathrm{V}_{1}\left(\mathrm{c}_{1}\right), \ldots, \Delta \mathrm{V}_{\mathrm{k}}\left(\mathrm{c}_{\mathrm{j}}\right), \ldots, \Delta \mathrm{V}_{\mathrm{kmax}}\left(\mathrm{c}_{\mathrm{jmax}}\right)\right.$, $\left.\Delta \Delta \mathrm{V}_{1}\left(\mathrm{c}_{1}\right), \ldots, \Delta \Delta \mathrm{V}_{\mathrm{k}}\left(\mathrm{c}_{\mathrm{j}}\right), \ldots, \Delta \Delta \mathrm{V}_{\mathrm{kmax}}\left(\mathrm{c}_{\mathrm{jmax}}\right)\right]$ are the inputs of this model. Each vector, $\mathrm{v}_{\mathrm{i}}$, represents a statistical case (ith case) out of a total of $n=407655$ cases (perturbations). These statistical cases encoded by $v_{i}$ vectors are perturbations of one entry or state of reference (changes in input parameters) that yield an output or new state. The input vectors $v_{i}$ include the value of $f\left(\varepsilon_{i j}\right)_{\text {ref }}$ for the state of reference (known value). The vectors $v_{i}$ also take into account the amounts of $\omega-6$ and $\omega-3$ for the new state (after perturbation). The values of molecular descriptors $\left({ }^{\mathrm{i}} \mathrm{V}_{\mathrm{k}}\right)$ used in a classic Hansch analysis were also included. Last, the inputs also consider the values of the PT-LFER operators $\Delta \Delta \mathrm{V}_{\mathrm{k}}\left(\mathrm{c}_{\mathrm{j}}\right)$. 


\subsubsection{Calculation of molecular descriptors.}

In the first work of this series, we used the mean values of atomic electronegativity of the chemical structure descriptors $\left({ }^{\mathrm{i}} \mathrm{V}_{\mathrm{k}}\right)$ of a drug. ${ }^{39}$ In another recent work, the method for the prediction of peptide epitopes was adapted using the perturbation theory. ${ }^{40}$ In the present work, the previous PT models are extended to other directions. Herein, PT models and Hansch's LFER equations are combined to carry out a PT-LFER analysis for the first time. To this end, the following steps were taken. First, structural variables $\left({ }^{\mathrm{i}} \mathrm{V}_{\mathrm{k}}\right)$ were used as a new set of molecular descriptors. The values of these variables were calculated using the DRAGON software. ${ }^{41-43}$ The first molecular descriptor calculated was $\mathrm{V}_{1}=\mathrm{Mw}$ (Molecular weight). The molecular descriptors $\mathrm{V}_{2}=$ AEigv, $\mathrm{V}_{3}=$ AEige, and $\mathrm{V}_{4}=$ AEigp were included, which are the average eigenvalues of the topological distance matrices weighted with atomic van der Waals volumes (v), polarizabilities (p), or electronegativities (e). Last, $\mathrm{V}_{5}=\mathrm{MR}$ (Molecular Refractivity) and $\mathrm{V}_{6}=\log \mathrm{P}$ (logarithm of the $\mathrm{n}$-octanol/water partition coefficient) were also proposed. The structures of fatty acids were uploaded to DRAGON in a form of Simplified Molecular-Input Line Entry System (SMILES) codes. SMILES codes are very useful to manage molecular structures ${ }^{44-46}$ and for further calculations of molecular descriptors ${ }^{21,47}$ (Table 1). In our work, the SMILES codes of corresponding fatty acids were downloaded from the website data of Chemical Entities of Biological Interest (ChEBI: http://www.ebi.ac.uk/chebi/).

\subsubsection{Calculation of PT operators.}

When the previous equation of the PT-LFER model was expanded, two types of input terms can be observed. The first type of term is the function $\mathrm{f}\left(\varepsilon_{\mathrm{ij}}\right)_{\text {ref. }}$. This function takes the values, $\mathrm{f}\left(\varepsilon_{\mathrm{ij}}\right)_{\text {ref }}=\left\langle\varepsilon_{\mathrm{ij}}\right\rangle_{\text {ref }}=$ $\operatorname{IPA}(\%)_{\mathrm{i}}$ for each sample. IPA $(\%)_{\mathrm{i}}=100 \cdot\left(\mathrm{PA}_{\mathrm{i}} / \mathrm{PA}_{\text {jmax }}\right)$ is the internal peak area proportion, used to quantify the experimental proportion of a fatty acid determined by GC. It means that $f\left(\varepsilon_{i j}\right)_{\text {ref }}$ is the measured value of the proportion of a fatty acid under the same conditions $c_{j}$. The second class refers to the perturbation terms $\Delta \Delta \mathrm{V}_{\mathrm{k}}\left(\mathrm{c}_{\mathrm{j}}\right)$. The parameters $\Delta \Delta \mathrm{V}_{\mathrm{k}}\left(\mathrm{c}_{\mathrm{j}}\right)$ are useful to quantify the effect of perturbations of different boundary conditions $\left(c_{j}\right)$ over the output ' $f\left(L_{n r}\right)_{n e w}$, which was defined herein as a discrete value function (occurrence or not of links in the network) for the classification purposes. The difference $\Delta \Delta \mathrm{V}_{\mathrm{k}}\left(\mathrm{c}_{\mathrm{j}}\right)$ between the final or new state $\left(\Delta \mathrm{V}_{\mathrm{k}}\left(\mathrm{c}_{\mathrm{j}}\right)_{\text {new }}\right)$ and the initial or reference state $\left(\Delta \mathrm{V}_{\mathrm{k}}\left(\mathrm{c}_{\mathrm{j}}\right)_{\mathrm{ref}}\right)$ is the additive perturbation for a component in $\Delta \mathrm{V}_{\mathrm{k}}\left(\mathrm{c}_{\mathrm{j}}\right)$. When the output of this equation is 'f( $\left(\mathrm{L}_{\text {nr }}\right)_{\text {new }}>$ ' $\mathrm{f}\left(\mathrm{L}_{\text {nr }}\right)_{\text {ref }} \Rightarrow \mathrm{L}_{\text {nr }}=1 \Rightarrow \operatorname{IPA}(\%)_{\text {new }}>\operatorname{IPA}(\%)_{\text {ref }}$ consequently $\left.\Rightarrow\right)$ the distribution or proportion of the FA in the new state is higher than that in the reference state, otherwise $\mathrm{L}_{\mathrm{nr}}=0$.

$$
\begin{gathered}
{ }^{\prime} f\left(L_{\mathrm{nr}}\right)_{\mathrm{new}}=a_{0}+a_{1} \cdot{ }^{\prime} f\left(L_{\mathrm{nr}}\right)_{\mathrm{ref}}+a_{1} \cdot\left\langle\varepsilon_{i j}\right\rangle_{\mathrm{ref}}+\sum_{j=1, k=1}^{j=j_{\max }, k=k_{\max }} a_{i j k} \cdot \Delta\left({ }^{i} V_{k}-\left\langle V_{k}\left(c_{j}\right)\right\rangle\right) \\
\Delta \Delta V_{k}\left(c_{j}\right)=p\left(c_{j}\right)_{\mathrm{new}} \cdot\left({ }^{i} V_{k}-\left\langle V_{k}\left(c_{j}\right)\right\rangle\right)_{\mathrm{new}}-p\left(c_{j}\right)_{\mathrm{ref}} \cdot\left({ }^{i} V_{k}-\left\langle V_{k}\left(c_{j}\right)\right\rangle\right)_{\mathrm{ref}}
\end{gathered}
$$


Table 1 Molecular descriptors $\left({ }^{\mathrm{i}} \mathrm{V}_{\mathrm{k}}\right)$ of fatty acids obtained from the ChEBI database

\begin{tabular}{|c|c|c|c|c|c|c|c|}
\hline \multirow[b]{2}{*}{ Name of fatty acids in $\mathrm{ChEBI}^{a}$} & \multirow[b]{2}{*}{ cis/trans pattern ${ }^{b}$} & \multicolumn{6}{|c|}{ Molecular descriptors of FA-inputs ${ }^{c}$} \\
\hline & & $\mathrm{V}_{1}$ & $\mathrm{~V}_{2}$ & $\mathrm{~V}_{3}$ & $\mathrm{~V}_{4}$ & $\mathrm{~V}_{5}$ & $\mathrm{~V}_{6}$ \\
\hline Lauric acid & 1 & 200.4 & 137.4 & 127.6 & 139.5 & 58.7 & 4.5 \\
\hline Myristic acid & 1 & 228.4 & 179.1 & 169.0 & 181.2 & 67.9 & 5.5 \\
\hline Myristoleic acid & $\mathrm{c}$ & 226.4 & 172.1 & 162.0 & 174.2 & 69.0 & 5.0 \\
\hline Pentadecanoic acid & 1 & 242.5 & 202.0 & 191.8 & 204.1 & 72.5 & 5.9 \\
\hline cis-10-Pentadecenoic acid & $\mathrm{c}$ & 240.4 & 194.8 & 184.5 & 196.9 & 73.6 & 5.5 \\
\hline Palmitic acid & 1 & 256.5 & 226.3 & 216.0 & 228.4 & 77.1 & 6.4 \\
\hline Palmitoleic acid & $\mathrm{c}$ & 254.5 & 217.9 & 207.6 & 220.1 & 78.2 & 5.9 \\
\hline Heptadecanoic acid & 1 & 270.5 & 252.0 & 241.6 & 254.1 & 81.7 & 6.8 \\
\hline Stearic acid cis-10-heptadecenoic acid & $\mathrm{c}$ & 268.5 & 243.2 & 232.8 & 245.4 & 82.8 & 6.4 \\
\hline Stearic acid & 1 & 284.5 & 279.1 & 268.6 & 281.2 & 86.3 & 7.3 \\
\hline Elaidic acid & $\mathrm{t}$ & 282.5 & 269.5 & 259.0 & 271.7 & 87.4 & 6.8 \\
\hline Oleic acid & $\mathrm{c}$ & 282.5 & 269.5 & 259.0 & 271.7 & 87.4 & 6.8 \\
\hline Linolelaidic acid & $\mathrm{tt}$ & 280.5 & 260.9 & 250.4 & 263.1 & 88.5 & 6.4 \\
\hline Linoleic acid & $\mathrm{cc}$ & 280.5 & 260.9 & 250.4 & 263.1 & 88.5 & 6.4 \\
\hline Arachidic acid & 1 & 312.6 & 337.4 & 326.8 & 339.6 & 95.5 & 8.2 \\
\hline$\gamma$-Linolenic acid & $\mathrm{ccc}$ & 278.5 & 251.5 & 240.9 & 253.7 & 89.6 & 5.9 \\
\hline Linolenic acid & $\mathrm{ccc}$ & 278.5 & 255.1 & 244.5 & 257.3 & 89.6 & 5.9 \\
\hline cis-11.14-Eicosadienoic acid & ct & 308.6 & 318.0 & 307.3 & 320.2 & 97.7 & 7.3 \\
\hline Behenic acid & 1 & 340.7 & 401.3 & 390.6 & 403.5 & 104.7 & 9.1 \\
\hline cis-8.11.14-Eicosatrienoic acid & $\mathrm{ctt}$ & 306.5 & 307.4 & 296.7 & 309.7 & 98.8 & 6.9 \\
\hline Erucic acid & $\mathrm{t}$ & 338.6 & 390.2 & 379.4 & 392.4 & 105.8 & 8.7 \\
\hline Acetic acid & 1 & 60.1 & 13.1 & 6.4 & 14.4 & 12.6 & -0.2 \\
\hline Propionic acid & 1 & 74.1 & 19.2 & 11.8 & 20.7 & 17.3 & 0.4 \\
\hline Isobutyric acid & 1 & 88.1 & 24.6 & 16.7 & 26.2 & 21.8 & 0.9 \\
\hline Butyric acid & 1 & 88.1 & 26.7 & 18.8 & 28.3 & 21.9 & 0.9 \\
\hline Isovaleric acid & 1 & 102.2 & 33.2 & 24.9 & 34.9 & 26.4 & 1.1 \\
\hline Valeric acid & 1 & 102.2 & 35.6 & 27.4 & 37.4 & 26.5 & 1.3 \\
\hline
\end{tabular}

a Fatty acids measured for our linear discriminant analysis PT-LFER model. b cis/trans pattern, 1 represents linear, and c represents cis-, and $t$ represents trans-PUFAs. The order of $\mathrm{c}$ or $\mathrm{t}$ represents the order of initial isomerization characteristics with the tails of PUFAs. $\mathrm{c}$ Molecular descriptors $\left({ }^{\mathrm{i}} \mathrm{V}_{\mathrm{k}}\right)$ calculated using DRAGON software: $\mathrm{V}_{1}=\mathrm{Mw}, \mathrm{V}_{2}=$ Aeigv, $\mathrm{V}_{3}=$ Aeige, $\mathrm{V}_{4}=$ Aeigp, $\mathrm{V}_{5}=$ $\mathrm{AMR}$, and $\mathrm{V}_{6}=\log \mathrm{P}$. 


\subsubsection{Calculation of Box-Jenkins operators.}

A close inspection of the perturbation terms shows that they are probability-weighted differences $(\Delta)$ of Box-Jenkins operators $\Delta \mathrm{V}_{\mathrm{k}}\left(\mathrm{c}_{\mathrm{j}}\right)$. The values of Box-Jenkins operators $\Delta \mathrm{V}_{\mathrm{k}}\left(\mathrm{c}_{\mathrm{j}}\right)$ of the molecular descriptors $\left({ }^{i} V_{k}\right)$ were calculated to quantify the effect of deviations of a molecule $\left(\mathrm{m}_{\mathrm{i}}\right)$ from the average behavior of all molecules measured under the same set of conditions $\left(c_{j}\right)$ of the complex system. Deviations due to the changes in different boundary conditions $\left(c_{j}\right)$ were taken into account. The boundary conditions refer to preliminary operational conditions, $c_{1}$ refers to the use of different experimental treatments, $c_{2}$ is with/without fermentation, $c_{4}$ is the gas chromatography protocol used, and $c_{5}$ refers to the use of replicate experiments. Others are more directly related to the posterior distribution and nature of the FA, $c_{3}$ is the biological phase of distribution of LCFAs, and $\mathrm{c}_{6}$ quantifies information about the cis/trans geometric pattern present in the LCFAs. All data were processed in an Excel file. In the Excel, the values of $\Delta \mathrm{V}_{\mathrm{k}}\left(\mathrm{c}_{\mathrm{j}}\right)$ were calculated considering various experimental boundary conditions $\left(c_{j}\right)$. The probabilities are $p\left(c_{j}\right)=n_{j} / n_{\text {total }} ; n_{j}$ is the number of experimental entries for condition $c_{j}$ and $n_{\text {total }}$ $=744$ total number of experimental entries (the total number of IPA $(\%)$ measured in this work). The average value $\left\langle\Delta \mathrm{V}_{\mathrm{k}}\left(\mathrm{c}_{\mathrm{j}}\right)\right\rangle$ (Table 2) is the difference in the function value ${ }^{\mathrm{i}} \mathrm{V}_{\mathrm{k}}$ with the average molecular descriptors $\left\langle\mathrm{V}_{\mathrm{k}}\right\rangle$ for a specific boundary condition $\mathrm{c}_{\mathrm{j}}$, see the equations:

$$
\Delta V_{k}\left(c_{j}\right)=\left({ }^{i} V_{k}-\left\langle V_{k}\left(c_{j}\right)\right\rangle\right) \quad\left\langle V_{k}\left(c_{j}\right)\right\rangle=\frac{1}{n_{j}}\left(\sum_{m_{i} \subset c_{j}}^{n_{j}}{ }^{i} V_{k}\right)
$$


Table 2 Average values of input variables $\left(\left\langle\mathrm{V}_{\mathrm{k}}\right\rangle\right)$ for experimental boundary conditions $\left(\mathrm{c}_{\mathrm{j}}\right)$

\begin{tabular}{|c|c|c|c|c|c|c|c|c|}
\hline \multicolumn{2}{|c|}{ Experimental boundary condition } & \multicolumn{4}{|c|}{ Average eigenvalues of input variables } & \multicolumn{2}{|c|}{$\left\langle\mathrm{V}_{\mathrm{k}}\left(\mathrm{c}_{\mathrm{j}}\right)^{g}\right.$} & \multirow{2}{*}{$\mathrm{p}\left(\mathrm{c}_{\mathrm{j}}\right)^{h}$} \\
\hline Conditions $\left(\mathrm{c}_{\mathrm{j}}\right)$ & Level & $\mathrm{V}_{1}$ & $\mathrm{~V}_{2}$ & $\mathrm{~V}_{3}$ & $\mathrm{~V}_{4}$ & $\mathrm{~V}_{5}$ & $\mathrm{~V}_{6}$ & \\
\hline \multirow[t]{6}{*}{$\mathrm{c}_{1} \Rightarrow$ treatments $^{a}$} & $\mathrm{BM}$ & 274.4 & 258.3 & 247.9 & 260.5 & 84.8 & 6.6 & 0.113 \\
\hline & $\mathrm{AM}$ & 274.4 & 258.3 & 247.9 & 260.5 & 84.8 & 6.6 & 0.113 \\
\hline & $\mathrm{CM}$ & 274.4 & 258.3 & 247.9 & 260.5 & 84.8 & 6.6 & 0.113 \\
\hline & BA & 261.9 & 234.6 & 224.3 & 236.8 & 80.3 & 6.2 & 0.258 \\
\hline & PA & 261.9 & 234.6 & 224.3 & 236.8 & 80.3 & 6.2 & 0.258 \\
\hline & MA & 85.8 & 25.4 & 17.7 & 27.0 & 21.1 & 0.7 & 0.145 \\
\hline \multirow[t]{2}{*}{$c_{2} \Rightarrow$ fermentation $^{b}$} & 0 & 274.4 & 258.3 & 247.9 & 260.5 & 84.8 & 6.6 & 0.339 \\
\hline & 1 & 223.2 & 188.7 & 178.9 & 190.7 & 67.3 & 5.0 & 0.661 \\
\hline \multirow[t]{3}{*}{$\mathrm{c}_{3} \Rightarrow$ phase $^{c}$} & Bacterial fraction & 269.0 & 248.1 & 237.7 & 250.3 & 82.9 & 6.4 & 0.597 \\
\hline & Protozoan fraction & 261.9 & 234.6 & 224.3 & 236.8 & 80.3 & 6.2 & 0.258 \\
\hline & Media fraction & 85.8 & 25.4 & 17.7 & 27.0 & 21.1 & 0.7 & 0.145 \\
\hline \multirow[t]{2}{*}{$\mathrm{c}_{4} \Rightarrow$ column of $\mathrm{GC}^{d}$} & HP-88 (112-88A7) & 266.8 & 244.0 & 233.6 & 246.2 & 82.1 & 6.4 & 0.855 \\
\hline & DB-FFAP & 85.8 & 25.4 & 17.7 & 27.0 & 21.1 & 0.7 & 0.145 \\
\hline \multirow[t]{4}{*}{$\mathrm{c}_{5} \Rightarrow$ replicate $(\mathrm{r} \text {-error })^{e}$} & 0 & 242.8 & 213.9 & 203.8 & 216.0 & 73.9 & 5.6 & 0.391 \\
\hline & 0.1 & 242.8 & 213.9 & 203.8 & 216.0 & 73.9 & 5.6 & 0.391 \\
\hline & 0.2 & 205.8 & 173.6 & 164.2 & 175.6 & 61.6 & 4.4 & 0.133 \\
\hline & 0.3 & 274.4 & 258.3 & 247.9 & 260.5 & 84.8 & 6.6 & 0.085 \\
\hline \multirow[t]{13}{*}{$\mathrm{c}_{6} \Rightarrow \mathrm{cis} / \mathrm{trans}$ pattern ${ }^{f}$} & linear & 203.2 & 180.8 & 171.5 & 182.8 & 59.6 & 4.6 & 0.238 \\
\hline & cis & 278.5 & 269.1 & 258.6 & 271.3 & 86.1 & 6.7 & 0.111 \\
\hline & trans & 310.6 & 329.8 & 319.2 & 332.1 & 96.6 & 7.7 & 0.032 \\
\hline & trans, trans & 280.5 & 260.9 & 250.4 & 263.1 & 88.5 & 6.4 & 0.016 \\
\hline & cis, cis & 308.6 & 320.8 & 310.1 & 323.0 & 97.7 & 7.3 & 0.032 \\
\hline & cis, trans & 289.9 & 279.6 & 269.0 & 281.8 & 91.6 & 6.7 & 0.048 \\
\hline & trans, cis & 280.5 & 261.1 & 250.5 & 263.3 & 88.5 & 6.4 & 0.016 \\
\hline & cis, cis, cis & 286.5 & 269.9 & 259.3 & 272.1 & 92.3 & 6.2 & 0.111 \\
\hline & cis, trans, trans & 292.5 & 280.0 & 269.3 & 282.2 & 94.2 & 6.4 & 0.032 \\
\hline & $\operatorname{trans}$, cis, trans & 278.5 & 254.6 & 244.0 & 256.8 & 89.6 & 5.9 & 0.016 \\
\hline & trans, trans, trans & 278.5 & 252.0 & 241.4 & 254.2 & 89.6 & 5.9 & 0.032 \\
\hline & cis, cis, trans & 278.5 & 252.5 & 241.9 & 254.8 & 89.6 & 5.9 & 0.016 \\
\hline & cis, trans, cis & 278.5 & 252.0 & 241.4 & 254.2 & 89.6 & 5.9 & 0.032 \\
\hline
\end{tabular}

\footnotetext{
a "BM" means base methylation without fermentation; "AM" means acid methylation without fermentation; "CM" means acid- and base-combined methylation; "BA" means fatty acids from bacterial fraction after $48 \mathrm{~h}$ of fermentation; "PA" means fatty acids from protozoan fraction after $48 \mathrm{~h}$ of fermentation; "MA" means volatile fatty acids from media fraction after $48 \mathrm{~h}$ of fermentation. $\mathrm{b}$ " 0 " means the dataset from experiment 1 without fermentation; "1" means the dataset from experiment 2 with fermentation of omega 6 and omega 3. " "Phase", means the dataset: long chain fatty acids including from the bacterial membrane (bacterial fraction), protozoan membrane (protozoan fraction), volatile fatty acids from fermentation media (media fraction). d Column of GC, "HP-88 (112-88A7)" means the column of GC for determining long chain fatty acids; "DB-FFAP" means the column for determining volatile fatty acids. e " 0 " means the original data, " $0.1,0.2$, or 0.3 " means the 1,2 , or 3 replicates, respectively. f cis/trans pattern: "linear" means LCFAs without double bonds; "cis" means LCFAs with cis isomerization; "trans" means LCFAs with trans isomerization; and the number of cis or trans means LCFAs with the same number of cis or trans double bonds. $\mathrm{g}_{\mathrm{k}}\left\langle\mathrm{V}_{\mathrm{k}}\left(\mathrm{c}_{\mathrm{j}}\right)\right\rangle \quad$ means the average of molecular descriptors $\left(\mathrm{V}_{\mathrm{k}}\right)$ for different conditions $\left(\mathrm{c}_{\mathrm{j}}\right)$; the descriptors are $\mathrm{V}_{1}=\mathrm{Mw}, \mathrm{V}_{2}=$ Aeigv, $\mathrm{V}_{3}=$ Aeige, $\mathrm{V}_{4}=$ Aeigp, $V_{5}=A M R$, and $V_{6}=\log P . h p\left(c_{j}\right)=n_{j} / n_{\text {total }} ; n_{j}$ number of experimental entries for conditions $c_{j}$ and $n_{\text {total }}=744$ total number of experimental entries.
} 


\subsubsection{Dataset.}

Predicting the effect of perturbations in input conditions over the output properties is the aim of this model. For this, we need to infer the value of the property in a new set of conditions using a known experimental value as reference. It means that we need to predict the variation of the experimental properties for pairs of data cases (reference and new). Consequently, if we have an original dataset with $n$ cases we need to explore a total of $\mathrm{n}^{2}$ cases for an exhaustive investigation of the data space (all pairs of data). If $\mathrm{n}$ is large, the number of pairs increases notably. Consequently, we carry out a random sampling procedure. We generated as many as possible pairs of data that we can process with a MS Excel sheet selecting at random both the reference and the new state. If a random MS Excel function has been used to generate pairs of random numbers between one and n, the very high number of 407655 perturbations was the higher number of pairs of cases we were able to handle in the Excel with our processing power.

\subsubsection{Classification models.}

The Linear Discriminant Analysis (LDA) ${ }^{38}$ algorithm implemented in the STATISTICA software was used to find the best PT-LFER model. Sometimes the relationship between the input variables and the output is more complex and the linearity cannot solve the problem. Therefore, the non-linear models could provide a better solution, but with the drawback of not being able to interpret the model and the relations between the variables. Thus, the Artificial Neural Networks (ANNs) ${ }^{48}$ were tested: Linear Neural Networks (LNNs), which are similar to the LDA models, and non-linear Multi-Layer Perceptrons (MLPs). ${ }^{38}$ The full datasets were randomly split into training series ("t", 75\%) used for model construction and validation series ("v", 25\%) used for model validation. In addition, a cross-validation variable was added to the dataset with the test values of " $t$ " and " $v$ ". All independent variables were unified and standardized using the STATISTICA software, prior to model construction.

\subsubsection{Complex network study.}

Both the observed and predicted networks were constructed in the Excel and saved in the .net (lists of pairs of nodes) file format. The links of the observed network coincide with the classes to be predicted by the previous LDA model. If the existence of a link corresponding to the condition $\mathrm{L}_{\mathrm{nr}}=1$, means $\operatorname{IPA}(\%)_{\mathrm{obs}}>\operatorname{IPA}(\%)_{\text {ref }}$ for each fatty acid at both the initial and final states; or $\mathrm{L}_{\mathrm{nr}}=0$ otherwise. A number of pairs of states as high as possible was generated, calculating the existence of observed links with the previous rule, and they were also predicted using the model. These files were processed using the CentiBiN software described by Junker et al., ${ }^{49}$ to calculate the average indices of the topology of the network. The indices calculated were the average values of the vertex-vertex topological distance, ${ }^{50}$ node degree, and closeness of the giant component of the observed, predicted and the two similar random ones. Two models of random networks (random networks 1 and 2) were also built. The model of the random network selected was the Erdös-Rényi graph (ER), which is often used as a random network model.

\section{Results and discussion}

\subsection{Catalyzed methylation in ruminal microbes}

Saponification followed by methylation is a classic method for the preparation of FA methyl esters. Table 3 shows the results obtained in the experimental determination of the values of IPA(\%) after different acid-/base-methylations. This table reports the average and standard deviation (SD) values of IPA $(\%)$ for those fatty acids for the first time. In general, base-catalyzed methylation proceeds more rapidly under mild temperature conditions than acid-catalyzed reactions. ${ }^{51}$ 
Table 3 Internal peak area values, IPA $(\%)^{a}$, of LCFA profiles of ruminal mixed microbes by acid- and/or base-catalyzed methylation

\begin{tabular}{|c|c|c|c|c|c|c|c|}
\hline \multirow{2}{*}{ Name of fatty acids } & & \multicolumn{3}{|l|}{ Average $^{b}$} & \multicolumn{3}{|l|}{ SD } \\
\hline & & B & A & $A \& B$ & $\mathrm{~B}$ & A & $\mathrm{A} \& \mathrm{~B}$ \\
\hline Lauric acid & $\mathrm{C} 12: 0$ & 0.55 & 0.52 & 1.87 & 0.07 & 0.16 & 0.76 \\
\hline Myristic acid & $\mathrm{C} 14: 0$ & 1.06 & 1.24 & 2.12 & 0.05 & 0.26 & 0.69 \\
\hline Myritoleic acid & $\mathrm{C} 14: 1$ & 1.95 & 2.31 & 2.38 & 0.11 & 0.49 & 0.69 \\
\hline Pentadecanoic acid & $\mathrm{C} 15: 0$ & 1.20 & 1.47 & 1.60 & 0.02 & 0.35 & 0.43 \\
\hline cis-10-Pentadecenoic acid & $\mathrm{C} 15: 1$ & 0.40 & 0.53 & 0.68 & 0.08 & 0.10 & 0.25 \\
\hline Palmitic acid & $\mathrm{C} 16: 0$ & 17.91 & 18.86 & 19.70 & 0.54 & 1.73 & 0.98 \\
\hline Palmitoleic acid & $\mathrm{C} 16: 1$ & 1.85 & 2.30 & 2.14 & 0.07 & 0.32 & 0.18 \\
\hline Heptadecanoic acid & $\mathrm{C} 17: 0$ & 0.99 & 1.39 & 1.49 & 0.25 & 0.20 & 0.28 \\
\hline cis-10-Heptadecanoic acid & $\mathrm{C} 17: 1$ & 0.00 & 0.17 & 0.53 & 0.00 & 0.20 & 0.29 \\
\hline Stearic acid & C18:0 & 49.76 & 49.17 & 40.21 & 1.02 & 1.62 & 0.80 \\
\hline Elaidic acid & $\mathrm{C} 18: 1 \mathrm{n} 9 \mathrm{t}$ & 8.68 & 8.23 & 8.76 & 0.65 & 0.69 & 1.30 \\
\hline Oleic acid & $\mathrm{C} 18: 1 \mathrm{n} 9 \mathrm{c}$ & 9.00 & 8.69 & 8.17 & 0.09 & 0.88 & 2.12 \\
\hline Linolelaidic acid & $\mathrm{C} 18: 2 \mathrm{n} 6 \mathrm{t}$ & 0.65 & 0.74 & 0.85 & 0.04 & 0.05 & 0.64 \\
\hline Linoleic acid & $\mathrm{C} 18: 2 \mathrm{n} 6 \mathrm{c}$ & 2.37 & 2.63 & 2.81 & 0.06 & 0.11 & 0.36 \\
\hline Arachidic acid & C20:0 & 0.84 & 0.68 & 1.23 & 0.17 & 0.07 & 1.50 \\
\hline$\gamma$-Linolenic acid & C18:3 n6 & 0.45 & 0.58 & 0.80 & 0.06 & 0.14 & 0.34 \\
\hline Linolenic acid & $\mathrm{C} 18: 3 \mathrm{n} 3$ & 0.00 & 0.00 & 1.52 & 0.00 & 0.00 & 1.25 \\
\hline cis-11,14-Eicosadienoic acid & $\mathrm{C} 20: 2$ & 0.34 & 0.14 & 0.75 & 0.67 & 0.16 & 0.63 \\
\hline Behenic acid & $\mathrm{C} 22: 0$ & 0.59 & 0.13 & 1.33 & 0.15 & 0.15 & 0.78 \\
\hline $\begin{array}{l}\text { cis-8,11,14-Eicosatrienoic } \\
\text { acid }\end{array}$ & C20:3 n6 & 0.58 & 0.05 & 0.82 & 0.22 & 0.10 & 1.11 \\
\hline Erucic acid & $\mathrm{C} 22: 1 \mathrm{n} 9$ & 0.82 & 0.17 & 0.24 & 0.42 & 0.19 & 0.47 \\
\hline Unsaturated fatty acids & & 27.10 & 26.55 & 30.44 & 1.46 & 1.08 & 3.29 \\
\hline $\begin{array}{l}\text { Long chain fatty acids } \geq 18 \\
\text { carbons }\end{array}$ & & 74.07 & 71.20 & 67.50 & 0.95 & 3.51 & 3.76 \\
\hline $\begin{array}{l}18 \text { carbons unsaturated fatty } \\
\text { acids }\end{array}$ & & 21.15 & 20.88 & 22.91 & 0.68 & 1.46 & 4.03 \\
\hline cis-fatty acids & & 11.36 & 11.32 & 10.98 & 0.06 & 0.79 & 1.88 \\
\hline trans-fatty acids & & 9.34 & 8.97 & 9.61 & 0.61 & 0.64 & 1.89 \\
\hline Ratios (cis/trans) & & 1.22 & 1.26 & 1.14 & 0.07 & 0.05 & 0.11 \\
\hline $\begin{array}{l}\text { Ratios (stearic acid : palmitic } \\
\text { acid) }\end{array}$ & & 2.78 & 2.61 & 2.04 & 0.03 & 0.32 & 0.12 \\
\hline Odd-carbon fatty acids & & 2.60 & 3.56 & 4.30 & 0.31 & 0.59 & 0.85 \\
\hline $\begin{array}{l}\text { Even-carbon saturated fatty } \\
\text { acids }\end{array}$ & & 70.71 & 70.59 & 66.47 & 1.25 & 0.69 & 2.96 \\
\hline $\begin{array}{l}\text { Even-carbon unsaturated fatty } \\
\text { acids }\end{array}$ & & 26.70 & 25.85 & 29.23 & 1.52 & 1.13 & 3.76 \\
\hline $\begin{array}{l}\text { Saturated/unsaturated fatty } \\
\text { acids }\end{array}$ & & 2.69 & 2.77 & 2.28 & 0.19 & 0.15 & 0.40 \\
\hline
\end{tabular}

a Internal peak area values, $\operatorname{IPA}(\%)$, mean the relative proportion of different fatty acids in the corresponding individual sample. b "A" = acid methylation, "B" = base methylation, or "A\&B" = acid methylation with subsequent base methylation. Average and standard deviation (SD) of IPA(\%) values for long chain fatty acids.

\subsection{LCFA profiles in bacteria and protozoan}

This work is focused on the lipid metabolism of exogenous FAs by direct determination of the IPA(\%) values of LCFA from ruminal microbe/protozoan biological membranes, including FAs from bacterial (Table 4) and protozoan (Table 5) biological membranes under different experimental conditions $\left(\mathrm{c}_{\mathrm{j}}\right)$. 
Table 4 Internal peak area values, IPA $(\%)$, of LCFA profiles in bacterial fraction ${ }^{a}$

\begin{tabular}{|c|c|c|c|c|c|c|c|}
\hline \multirow{2}{*}{ Name of fatty acids } & \multicolumn{6}{|c|}{$\begin{array}{l}\text { Various exogenous } \omega-6 / \omega-3 \text { PUFA ratios (x : [100-x]; in total of } 100 \mathrm{mg} \mathrm{g}^{-1} \\
\text { substrate) }\end{array}$} & \multirow{2}{*}{ Average } \\
\hline & $100-0$ & $90-10$ & $80-20$ & $66-33$ & $50-50$ & $20-80$ & \\
\hline Lauric acid & 0.62 & 0.67 & 0.56 & 0.55 & 1.89 & 0.52 & 0.80 \\
\hline Myristic acid & 1.53 & 1.45 & 1.31 & 1.27 & 1.71 & 1.23 & 1.42 \\
\hline Myritoleic acid & 2.66 & 2.61 & 2.32 & 2.20 & 1.90 & 2.06 & 2.29 \\
\hline Pentadecanoic acid & 2.13 & 1.86 & 1.82 & 1.68 & 1.53 & 1.61 & 1.77 \\
\hline cis-10-Pentadecenoic acid & 0.83 & 0.73 & 0.64 & 0.58 & 0.45 & 0.44 & 0.61 \\
\hline Palmitic acid & 18.38 & 18.73 & 18.82 & 18.82 & 18.79 & 18.39 & 18.65 \\
\hline Palmitoleic acid & 1.45 & 1.91 & 1.97 & 1.29 & 1.72 & 1.94 & 1.71 \\
\hline Heptadecanoic acid & 1.77 & 2.16 & 2.01 & 1.73 & 1.65 & 1.92 & 1.87 \\
\hline cis-10-Heptadecenoic acid & 0.62 & 0.41 & 0.16 & 0.00 & 0.25 & 0.25 & 0.28 \\
\hline Stearic acid & 56.93 & 56.17 & 58.64 & 58.97 & 58.22 & 57.58 & 57.75 \\
\hline Elaidic acid & 5.95 & 6.61 & 5.71 & 5.59 & 4.89 & 5.01 & 5.63 \\
\hline Oleic acid & 2.93 & 3.86 & 3.07 & 3.59 & 3.90 & 5.33 & 3.78 \\
\hline Linolelaidic acid & 2.09 & 0.97 & 1.18 & 1.65 & 1.05 & 1.47 & 1.40 \\
\hline Linoleic acid & 1.03 & 1.07 & 1.04 & 1.02 & 1.24 & 1.62 & 1.17 \\
\hline Arachidic acid & 0.56 & 0.59 & 0.46 & 0.68 & 0.55 & 0.33 & 0.53 \\
\hline$\gamma$-Linolenic acid & 0.53 & 0.22 & 0.28 & 0.37 & 0.25 & 0.31 & 0.33 \\
\hline Unsaturated fatty acids, $\%$ & 18.07 & 18.38 & 16.38 & 16.29 & 15.66 & 18.43 & 17.20 \\
\hline $\begin{array}{l}\text { Long chain fatty acids } \geq 18 \text { carbons, } \\
\%\end{array}$ & 70.02 & 69.49 & 70.39 & 71.87 & 70.09 & 71.65 & 70.58 \\
\hline 18 carbon unsaturated fatty acids, $\%$ & 12.52 & 12.73 & 11.28 & 12.22 & 11.33 & 13.74 & 12.30 \\
\hline cis-Fatty acids, $\%$ & 3.95 & 4.93 & 4.12 & 4.61 & 5.13 & 6.95 & 4.95 \\
\hline trans-Fatty acids, $\%$ & 8.04 & 7.58 & 6.89 & 7.24 & 5.94 & 6.48 & 7.03 \\
\hline Ratios (cis-/trans-) & 0.492 & 0.650 & 0.598 & 0.637 & 0.864 & 1.072 & 0.72 \\
\hline Ratios (stearic acid : palmitic acid) & 3.098 & 2.999 & 3.116 & 3.134 & 3.098 & 3.131 & 3.10 \\
\hline Odd-carbon fatty acids, $\%$ & 5.34 & 5.15 & 4.63 & 4.00 & 3.89 & 4.22 & 4.54 \\
\hline Even-carbon saturated fatty acids, $\%$ & 78.03 & 77.60 & 79.80 & 80.29 & 81.16 & 78.04 & 79.15 \\
\hline $\begin{array}{l}\text { Even-carbon unsaturated fatty acids, } \\
\%\end{array}$ & 16.63 & 17.24 & 15.58 & 15.71 & 14.95 & 17.74 & 16.31 \\
\hline Saturated/unsaturated fatty acids & 4.53 & 4.44 & 5.11 & 5.14 & 5.39 & 4.43 & 4.81 \\
\hline
\end{tabular}

a Internal peak area values, IPA(\%), mean the relative proportion (\%) of different fatty acids in the corresponding individual sample. 
Table 5 Internal peak area values, IPA(\%), of LCFAs in protozoan fraction ${ }^{a}$

\begin{tabular}{|c|c|c|c|c|c|c|c|}
\hline \multirow{2}{*}{ Name of fatty acids } & \multicolumn{6}{|c|}{$\begin{array}{l}\text { Various exogenous } \omega-6 / \omega-3 \text { PUFA ratios }\left(\mathrm{x}:[100-\mathrm{x}] \text {; in total of } 100 \mathrm{mg} \mathrm{g}^{-1}\right. \\
\text { substrate) }\end{array}$} & \multirow{2}{*}{ Average } \\
\hline & $100-0$ & $90-10$ & $80-20$ & $66-33$ & $50-50$ & $20-80$ & \\
\hline Lauric acid & 0.61 & 0.50 & 1.09 & 0.25 & 0.28 & 0.21 & 0.49 \\
\hline Myristic acid & 0.76 & 1.07 & 1.16 & 0.73 & 0.93 & 0.68 & 0.89 \\
\hline Myritoleic acid & 0.63 & 0.96 & 0.88 & 0.75 & 0.87 & 0.59 & 0.78 \\
\hline Pentadecanoic acid & 0.79 & 1.24 & 1.04 & 0.93 & 1.00 & 0.73 & 0.96 \\
\hline cis-10-Pentadecenoic acid & 0.48 & 0.67 & 0.66 & 0.32 & 0.59 & 0.48 & 0.53 \\
\hline Palmitic acid & 11.39 & 13.46 & 15.78 & 13.16 & 14.07 & 11.93 & 13.30 \\
\hline Palmitoleic acid & 0.39 & 0.89 & 0.92 & 0.99 & 1.10 & 0.89 & 0.86 \\
\hline Heptadecanoic acid & 0.44 & 1.72 & 1.70 & 1.26 & 1.59 & 1.19 & 1.31 \\
\hline cis-10-Heptadecenoic acid & 0.20 & 0.15 & 0.17 & 0.17 & 0.19 & 0.10 & 0.16 \\
\hline Stearic acid & 71.29 & 66.40 & 63.53 & 68.44 & 66.89 & 68.55 & 67.52 \\
\hline Elaidic acid & 7.29 & 6.67 & 6.63 & 6.50 & 6.20 & 5.83 & 6.52 \\
\hline Oleic acid & 3.04 & 3.50 & 3.90 & 4.04 & 3.98 & 5.08 & 3.93 \\
\hline Linolelaidic acid & 0.69 & 0.59 & 0.60 & 0.88 & 0.95 & 2.25 & 0.99 \\
\hline Linoleic acid & 0.78 & 1.44 & 1.05 & 0.83 & 0.94 & 1.05 & 1.02 \\
\hline Arachidic acid & 1.01 & 0.42 & 0.53 & 0.47 & 0.24 & 0.31 & 0.50 \\
\hline$\gamma$-Linolenic acid & 0.21 & 0.33 & 0.35 & 0.28 & 0.16 & 0.14 & 0.24 \\
\hline Unsaturated fatty acids, $\%$ & 13.71 & 15.20 & 15.17 & 14.77 & 14.99 & 16.41 & 15.04 \\
\hline $\begin{array}{l}\text { Long chain fatty acids } \geq 18 \text { carbons, } \\
\%\end{array}$ & 84.31 & 79.34 & 76.60 & 81.45 & 79.37 & 83.21 & 80.71 \\
\hline $\begin{array}{l}18 \text { carbon unsaturated fatty acids, } \\
\%\end{array}$ & 12.01 & 12.52 & 12.54 & 12.54 & 12.24 & 14.36 & 12.70 \\
\hline cis-Fatty acids, $\%$ & 3.82 & 4.94 & 4.96 & 4.87 & 4.92 & 6.13 & 4.94 \\
\hline trans-fatty acids, $\%$ & 7.98 & 7.25 & 7.23 & 7.38 & 7.16 & 8.09 & 7.51 \\
\hline Ratios (cis-/trans-) & 0.480 & 0.681 & 0.685 & 0.661 & 0.688 & 0.758 & 0.66 \\
\hline Ratios (stearic acid : palmitic acid) & 6.258 & 4.933 & 4.027 & 5.202 & 4.753 & 5.746 & 5.15 \\
\hline Odd-carbon fatty acids, $\%$ & 1.90 & 3.78 & 3.56 & 2.68 & 3.37 & 2.50 & 2.96 \\
\hline $\begin{array}{l}\text { Even-carbon saturated fatty acids, } \\
\%\end{array}$ & 85.07 & 81.85 & 82.10 & 83.05 & 82.42 & 81.67 & 82.69 \\
\hline $\begin{array}{l}\text { Even-carbon unsaturated fatty } \\
\text { acids, } \%\end{array}$ & 13.04 & 14.38 & 14.34 & 14.28 & 14.21 & 15.83 & 14.34 \\
\hline Saturated/unsaturated fatty acids & 6.29 & 5.58 & 5.60 & 5.78 & 5.67 & 5.09 & 5.65 \\
\hline
\end{tabular}

a Internal peak area values, $\operatorname{IPA}(\%)$, mean the relative proportion $(\%)$ of different fatty acids in the corresponding individual sample.

It is well known that the imbalance of $\omega-6 / \omega-3$ ratios in the diet has the potential to induce inflammation, asthma, arthritis, and vascular diseases, ${ }^{52}$ but high levels of $\omega-3$ exert a suppressive effect. ${ }^{53-56}$ As expected, the FA composition of ruminal bacterial and protozoan biological membranes, and VFAs in media was indeed changeable with the exogenous $\omega-6 / \omega-3$ PUFA ratios. This study had no significant statistical difference in the main IPA $(\%)$ of fatty acids (e.g., C16:0, C18:0), but some valuable information has still been extracted from the results. First of all, cis-FA content increased with exogenous $\omega-3$ PUFAs, and trans-FAs decreased in the biological phase of bacteria. For example, the cis-FA profiles in $\omega-6 / \omega-3=20: 80$ were 1.76 times (bacterial phase) and 1.60 times (protozoan phase) than that in $\omega$ $6 / \omega-3=100: 0$, and trans-FA profiles in $\omega-6 / \omega-3=100: 0$ were 1.24 times (bacterial phase) and 0.98 time (protozoan phase) than that in $\omega-6 / \omega-3=20: 80$. This directly results in the increasing ratio of cis/trans-fatty acid compositions with the increase of the exogenous $\omega-3$ PUFAs, such as 2.18 times in the bacterial phase and 1.58 times in the protozoan phase, when $\omega-6 / \omega-3=20: 80$ compared with $\omega-6 / \omega-3=$ 100 : 0 , respectively. It means that exogenous PUFAs are degraded by rumen microorganisms, or have more complex metabolism processes leading to intermediary metabolism with both cis- and transunsaturated FA formulations. The biohydrogenation of linoleic acid (LA, cis 9, cis 12-C18:2) in rumen is 
isomerized to cis 9, trans 11-C18:2 isomer (conjugated linoleic acid, CLA), conversion of this isomer to trans 11-C18:1 (vaccenic acid), and reduction to stearic acid (C18:0) ${ }^{57}$ Whereas the bio-hydrogenation of $\alpha$-linolenic acid (ALA) is characterized by isomerization to 9, 11, 15-cis, trans, cis-C18:3 isomer and subsequent reduction via cis, trans isomers C18:2, C18:1 and then to stearic acid. ${ }^{58}$ This research showed that $\omega-3$ PUFAs ( $\alpha$-linolenic acid) could increase the cis-FA content compared to $\omega-6$ PUFAs (linoleic acid) on both of bacterial and protozoan phases.

Secondly, IPA values of $\mathrm{C} 16: 0$ and $\mathrm{C} 18: 0$ in the bacterial phase were $18.7 \%$ and $57.8 \%$, whereas those in the protozoan phase were $13.3 \%$ and $67.5 \%$, respectively. The exogenous $\omega-6 / \omega-3$ ratios have no significant effect on these two major fatty acids in both bacterial and protozoan phases. However, the minor difference in lipid composition like ratios of palmitic/stearic acid, or unsaturated/saturated fatty acids on bacterial and protozoan biological membranes may trigger a great difference in the function of membranes of bacteria and protozoa (e.g., membrane fluidity, permeability, hydrophobicity and stability), ${ }^{59,60}$ or further in the functional groups ${ }^{61,62}$ such as specific peptide, enzymes, or channels, etc. Stearic acid in a protozoan membrane is higher (about 14.0\%) than that in a bacterial membrane, unlike other fatty acids.

Thirdly, even-carbon saturated FAs in the treatment of $\omega-6 / \omega-3=100: 0$ and $\omega-6 / \omega-3=20: 80$ were $85.1 \%$ and $81.7 \%$ in the protozoan phase, whereas even-carbon unsaturated FAs in those treatments were $13.0 \%$ and $15.8 \%$, respectively (Table 5). Herein, the highest value of even-carbon unsaturated FA appeared in the treatment of $\omega-6 / \omega-3=20: 80$, this phenomenon also occurred in the bacterial phase, which means that, according to this study, a high amount of $\omega-3$ PUFAs has the tendency to increase the even-carbon unsaturated FAs compared to $\omega-6$ PUFAs.

An interesting fact is that linolelaidic acid $(\mathrm{C} 18: 2,6 \mathrm{t})$ proportion in $\omega-6 / \omega-3=100: 0$ was a little higher than other treatments in the bacterial phase, whereas a higher proportion appeared in the protozoan phase when $\omega-6 / \omega-3=20: 80$. This might be due to the biohydrogenation of PUFAs (such as linoleic and linolenic acid) in rumen resulting in the production of primarily trans-fatty acids and stearic acid. ${ }^{63}$ All the differences in fatty acid distributions between bacterial and protozoan phases can reflect protozoa and bacteria having a different and complex metabolism in the processes of assimilation, absorption, degradation or de novo synthesis. Thanks to these differences, that make the different phases (bacterial and protozoan phases), as important input variables, more reasonable in our new Hansch Perturbation Theory - LFER model. The LCFA and VFA distribution was stated in the entire fermentation system of a ruminal micro-niche environment, as shown in Fig. 3.

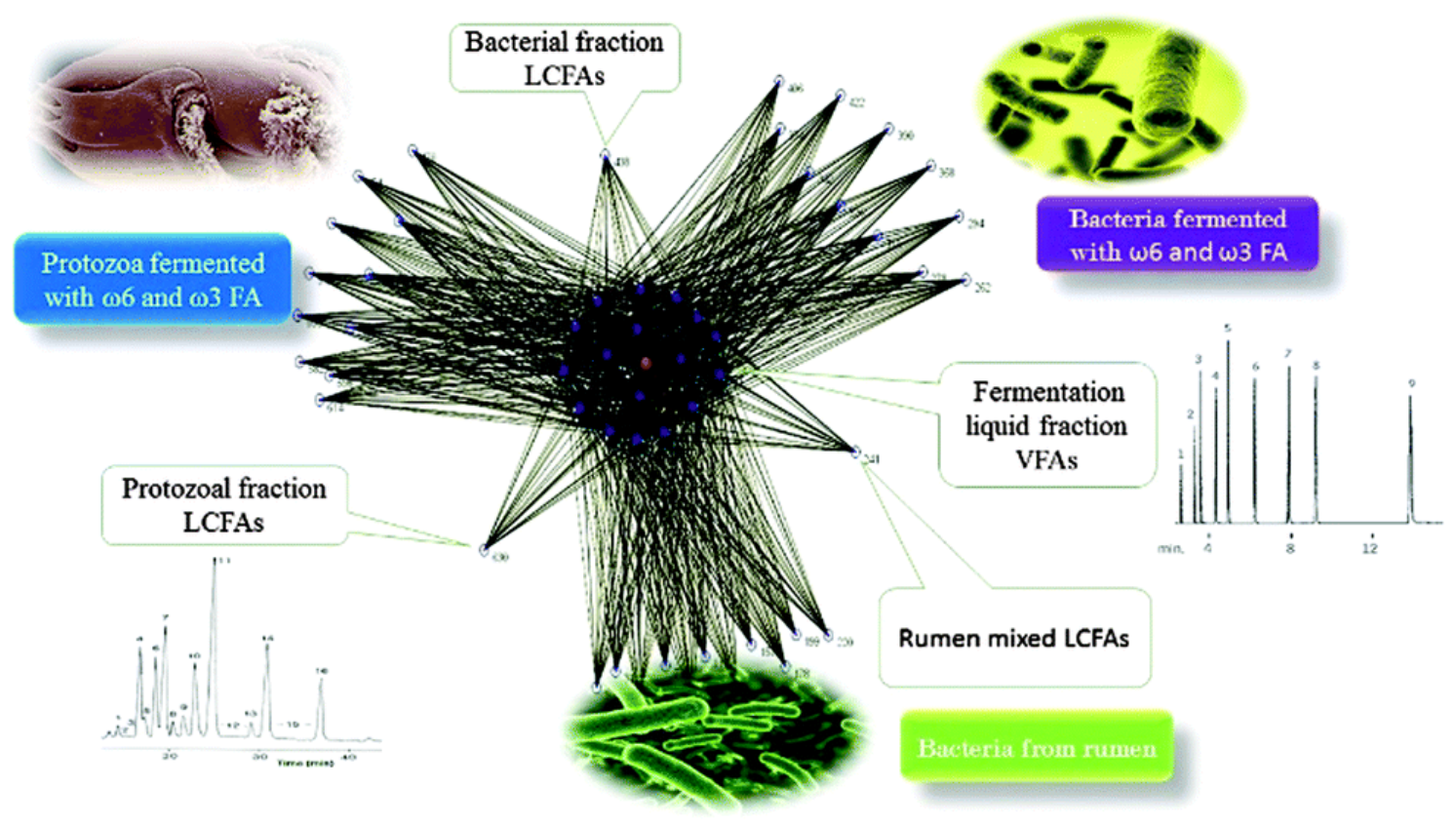

Fig. 3 Illustration of the sub-network of LCFAs and VFAs in rumen micro-niches. 


\subsection{VFA profiles in media provided with exogenous $\omega-6 / \omega-3$ PUFAs}

In this study, the peak area (PA) of VFAs was determined in each sample to calculate the internal peak area, IPA(\%), at $48 \mathrm{~h}$ fermentation. On the other hand, the absolute concentration of VFAs was also calculated, using the PA combined with the corresponding standard curve in the same situation (Table 6). Volatile fatty acids (VFAs) are widely regarded as secondary metabolites to reflect the hydrogenation metabolism of lipids, microbial degradation enzyme activity, and the lifecycle of microbial organisms in the rumen micro-ecological niche. ${ }^{64,65}$ The acetic, propionic and butyric acids are the major VFAs, with proportions of $43.6 \%, 23.1 \%$ and $19.2 \%$, respectively. Meanwhile, the residue VFAs, including isobutyric, isovaleric and valeric acid had a total proportion of $14.1 \%$. It is noteworthy that there was no significant difference in VFAs with the supply of different exogenous $\omega-6 / \omega-3$ PUFA ratios. The values of all VFAs in the treatment of $\omega-6 / \omega-3=80: 20$ were lower than others, which might be the result of the bottle cap of storage containers which was broken or was not sealed properly. However, this study is focused on the proportion peak areas of VFAs on the same sample or treatment. It can be concluded that acetic acid had a minor decrease, but propionic acid had a slight increase, with an increasing proportion of $\omega-3$ PUFAs in the total supplementation exogenous PUFAs. Even if both acetic acid and propionic acid changed a little in terms of different proportions of $\omega-6$ and $\omega-3$ PUFAs in a total of $100 \mathrm{mg} \mathrm{g}^{-1}$ of substrate, the ratio of acetic and propionic acid was regularly decreased, with increasing proportion of $\omega-3$ PUFAs with an average of 1.89 .

Table 6 Internal peak area values, IPA(\%), and absolute concentration (mM) of volatile fatty acids (VFAs) in media fraction ${ }^{a}$

\begin{tabular}{|c|c|c|c|c|c|c|c|}
\hline \multirow{2}{*}{ VFA name } & \multicolumn{6}{|c|}{$\begin{array}{l}\text { IPA }(\%) \text { values of VFAs supplemented with various exogenous } \omega-6 / \omega-3 \text { PUFA } \\
\text { ratios }^{b}\end{array}$} & \multirow{2}{*}{ Average } \\
\hline & $100-0$ & $90-10$ & $80-20$ & $66-33$ & $50-50$ & $20-80$ & \\
\hline Acetic acid & 44.72 & 43.86 & 43.61 & 43.62 & 42.83 & 42.74 & 43.56 \\
\hline Propionic acid & 22.80 & 22.62 & 22.90 & 23.15 & 23.36 & 23.66 & 23.08 \\
\hline Isobutyric acid & 2.48 & 2.57 & 2.78 & 2.37 & 2.39 & 2.65 & 2.54 \\
\hline Butyric acid & 18.31 & 19.06 & 19.55 & 19.21 & 19.66 & 19.62 & 19.24 \\
\hline Isovaleric acid & 5.93 & 5.99 & 5.84 & 5.89 & 5.77 & 5.81 & 5.87 \\
\hline Valeric acid & 5.77 & 5.89 & 5.32 & 5.77 & 5.99 & 5.51 & 5.71 \\
\hline Ac/Pro & 1.96 & 1.94 & 1.90 & 1.88 & 1.83 & 1.81 & 1.89 \\
\hline
\end{tabular}

\begin{tabular}{|c|c|c|c|c|c|c|c|}
\hline \multirow{2}{*}{ VFA name } & \multicolumn{6}{|c|}{ Absolute concentration $(\mathrm{mM})$ of VFAs supplemented with various exogenous $\omega-6 / \omega-3$ PUFA $\operatorname{ratios}^{c}$} & \multirow{2}{*}{$\left(\mathrm{r}^{2}\right)^{d}$} \\
\hline & $100-0$ & $90-10$ & $80-20$ & $66-33$ & $50-50$ & $20-80$ & \\
\hline Acetic acid & $124.4 \pm 1.66$ & $104.2 \pm 2.89$ & $75.6 \pm 2.26$ & $114.1 \pm 1.85$ & $109.4 \pm 1.01$ & $110.5 \pm 0.71$ & 0.9964 \\
\hline Propionic acid & $31.6 \pm 0.54$ & $26.8 \pm 0.71$ & $19.8 \pm 0.56$ & $30.2 \pm 0.59$ & $29.7 \pm 0.37$ & $30.5 \pm 0.22$ & 0.9974 \\
\hline Isobutyric acid & $2.3 \pm 0.04$ & $2.1 \pm 0.02$ & $1.6 \pm 0.07$ & $2.1 \pm 0.02$ & $2.1 \pm 0.02$ & $2.3 \pm 0.27$ & 0.9985 \\
\hline Butyric acid & $19.1 \pm 0.41$ & $16.9 \pm 0.87$ & $12.6 \pm 0.22$ & $18.8 \pm 1.15$ & $18.8 \pm 0.35$ & $19.0 \pm 0.10$ & 0.9983 \\
\hline Isovaleric acid & $5.0 \pm 0.11$ & $4.3 \pm 0.13$ & $3.1 \pm 0.10$ & $4.6 \pm 0.21$ & $4.4 \pm 0.04$ & $4.5 \pm 0.04$ & 0.9988 \\
\hline Valeric acid & $4.8 \pm 0.10$ & $4.2 \pm 0.10$ & $2.8 \pm 0.22$ & $4.5 \pm 0.03$ & $4.6 \pm 0.04$ & $4.3 \pm 0.25$ & 0.9986 \\
\hline Ac/Pro ${ }^{e}$ & $3.93 \pm 0.02$ & $3.89 \pm 0.01$ & $3.83 \pm 0.01$ & $3.78 \pm 0.02$ & $3.68 \pm 0.04$ & $3.63 \pm 0.01$ & - \\
\hline
\end{tabular}

a Internal peak area values, $\operatorname{IPA}(\%)$, mean the relative proportion $(\%)$ of different fatty acids in the same individual sample. $\mathrm{b}$ The entire supplementation amount of $\omega-6 / \omega-3$ PUFAs was standard: $100 \mathrm{mg} \mathrm{g}^{-1}$ alfalfa substrate, means \pm standard errors. . Standard curve was used to calculate the values of each VFA; the standard curve equation is $f(x)=a \cdot x+b$, with $f(x)=$ concentration of the VFAs, $x=$ Peak Area (PA), $a=$ coefficient of peak area, and $b=$ intercept. The values of $(a, b)$ found for different VFAs are as follows: for acetic acid (3 000 000; 3000 000), propionic acid (6 000 000; 1000 000), isobutyric acid (9 000 000; 465874 ), butyric acid (8 $000000 ; 767690)$, isovaleric acid (10 $000000 ; 501483)$, and valeric acid $(10000000 ; 644543)$ d $\mathrm{r}^{2}$ the correlation coefficient square of the standard curve for calculating each corresponding volatile fatty acid. e Ac/Pro $=$ the ratio of acetic acid with propionic acid. 


\subsection{PT-LFER model for a FA distribution network}

A new model was developed which is useful to predict the proportion of FAs (LCFAs and VFAs) in different phases of ruminal microbiome with/without exogenous PUFAs after perturbations in chemical molecular descriptors $\left(\mathrm{V}_{\mathrm{k}}\right)$ and under initial experimental boundary conditions $\left(\mathrm{c}_{\mathrm{j}}\right)$. Each value represents a corresponding coefficient in the new model for predicting the IPA $(\%)_{\text {new }}$ of each FA (Table 7). As explained, this model can classify as high $\left(\mathrm{L}_{\mathrm{nr}}=1\right) / \mathrm{low}\left(\mathrm{L}_{\mathrm{nr}}=0\right)$ the expected proportion of FAs (LCFA/VFA) between the new and reference states after changing the boundary conditions $c_{j}$. The parameter $n\left(L_{n r}=1\right)$ represents the number of cases in the sub-set with $L_{n r}=1$ (links in the network), or the same with IPA $(\%)_{\text {new }}$ of a new sub-set higher than that of reference IPA $(\%)_{\text {ref. }}$ On the other hand, $\mathrm{n}\left(\mathrm{L}_{\mathrm{nr}}=0\right)$ represents the number of cases observed and predicted in the sub-set with $\mathrm{L}_{\mathrm{nr}}=0$ (not connected nodes) or explained that the IPA $(\%)_{\text {new }}$ value is lower than the IPA $(\%)_{\text {ref }}$ value. The best PTLFER model found using the LDA algorithm has only 12 variables and it is described by the following algorithm.

$$
\begin{aligned}
{ }^{\prime} f\left(L_{\mathrm{nr}}\right)_{\mathrm{new}}= & -0.021 \cdot f\left(\varepsilon_{i j}\right)_{\mathrm{ref}}+0.0026 \cdot\left\langle f\left(\varepsilon_{i j}\right)\right\rangle_{\mathrm{ref}} \\
& +0.3713 \cdot{ }^{\mathrm{new}} V_{6}+1.0709 \cdot{ }^{\mathrm{new}} \omega 6-1.1264 \cdot{ }^{\mathrm{new}} \omega 3 \\
& +0.0237 \cdot \Delta \Delta V_{5}\left(c_{1}\right)-0.0063 \cdot \Delta \Delta V_{6}\left(c_{2}\right) \\
& +0.0044 \cdot \Delta \Delta V_{1}\left(c_{4}\right)-0.0037 \cdot \Delta \Delta V_{1}\left(c_{5}\right) \\
& -0.0036 \cdot \Delta \Delta V_{4}\left(c_{6}\right)-0.1682 \cdot\left({ }^{\mathrm{new}} V_{6}\right)^{2} \\
& +0.0182 \cdot\left(\Delta \Delta V_{6}\left(c_{3}\right)\right)^{2}-13.7236 \\
N= & 407,655 ; \quad \chi^{2}=244,532.9 ; \quad p<0.005
\end{aligned}
$$

Where, the output function ' $\mathrm{f}\left(\mathrm{L}_{\mathrm{nr}}\right)_{\text {new }}$ is a function of the connectivity pattern $\left(\mathrm{L}_{\mathrm{nr}}\right)$ in the complex network for the co-distribution of FAs in the reference and new state (predicted values). The output function ' $\mathrm{f}\left(\mathrm{L}_{\mathrm{nr}}\right)_{\text {new }}$ is useful to classify the pairs of states (pairs of nodes). The statistical parameters used were specificity $(\mathrm{Sp})$, sensitivity $(\mathrm{Sn})$, and accuracy $(\mathrm{Ac})$. Consequently, the other input terms were expanded as follows. For instance, $\Delta \Delta \mathrm{V}_{\mathrm{k}}\left(\mathrm{c}_{\mathrm{j}}\right)=\mathrm{p}\left(\mathrm{c}_{\mathrm{j}}\right)_{\text {new }} \cdot \Delta \mathrm{V}_{\mathrm{k}}\left(\mathrm{c}_{\mathrm{j}}\right)_{\text {new }}-\mathrm{p}\left(\mathrm{c}_{\mathrm{j}}\right)_{\text {ref }}\left(\Delta \mathrm{V}_{\mathrm{k}}\left(\mathrm{c}_{\mathrm{j}}\right)_{\text {ref }}\right)$. This can be further expanded in turn as $\Delta \Delta \mathrm{V}_{\mathrm{k}}\left(\mathrm{c}_{\mathrm{j}}\right)=\mathrm{p}\left(\mathrm{c}_{\mathrm{j}}\right)_{\text {new }}\left({ }^{\text {new }} \mathrm{V}_{\mathrm{k}}-\left\langle\mathrm{V}_{\mathrm{k}}\left(\mathrm{c}_{\mathrm{j}}\right)\right\rangle_{\text {new }}\right)-\mathrm{p}\left(\mathrm{c}_{\mathrm{j}}\right)_{\text {ref }}\left({ }^{\mathrm{ref}} \mathrm{V}_{\mathrm{k}}-\left\langle\mathrm{V}_{\mathrm{k}}\left(\mathrm{c}_{\mathrm{j}}\right)\right\rangle_{\text {ref }}\right)$, where \langle $\left.\mathrm{V}_{\mathrm{k}}\left(\mathrm{c}_{\mathrm{j}}\right)\right\rangle=$ average of $\mathrm{V}_{\mathrm{k}}$ for $\mathrm{c}_{\mathrm{j}}$. This new model found predicted the effects of perturbations under the initial conditions $\left(c_{j}\right)$ over FA distribution with sensitivity, specificity, and accuracy $>80 \%$ for a total of $=$ 303712 cases in training and = 103943 cases in external validation series (Table 8). These results are considered good for any LDA model. 
Table 7 Details of the PT-LFER model for the distribution network of fatty acids

\begin{tabular}{|c|c|c|c|c|}
\hline Coeff. & Variable $^{a}$ & Value & $\begin{array}{l}\text { Classic } \\
\text { symbols }^{b}\end{array}$ & PT operators $\left(\Delta \Delta \mathrm{V}_{\mathrm{k}}\left(\mathrm{c}_{\mathrm{j}}\right)\right)^{\mathrm{c}}$ \\
\hline $\mathrm{a}_{0}$ & Intercept & -13.7236 & - & - \\
\hline $\mathrm{a}_{1}$ & $\mathrm{f}\left(\varepsilon_{\mathrm{ij}}\right)_{\mathrm{ref}}$ & -0.0210 & - & - \\
\hline $\mathrm{a}_{2}$ & $\left\langle\mathrm{f}\left(\varepsilon_{\mathrm{ij}}\right)\right\rangle_{\text {ref }}$ & 0.0026 & - & - \\
\hline $\mathrm{a}_{3}$ & ${ }^{\text {new }} \mathrm{V}_{6}$ & 0.3713 & $\mathrm{~V}_{6}=\log \mathrm{P}$ & - \\
\hline $\mathrm{a}_{4}$ & ${ }^{\text {new }} V_{7}$ & 1.0709 & $\mathrm{~V}_{7}=(\log \mathrm{P})^{2}$ & - \\
\hline $\mathrm{b}_{5}$ & ${ }^{\mathrm{new}} \omega-6$ & -1.1264 & - & - \\
\hline $\mathrm{b}_{6}$ & ${ }^{\text {new }} \omega-3$ & 0.0237 & - & - \\
\hline $\mathrm{b}_{7}$ & $\Delta \Delta \mathrm{V}_{5}\left(\mathrm{c}_{1}\right)$ & -0.0063 & $\mathrm{~V}_{5}=\mathrm{MR}$ & $\begin{aligned}= & \Delta \mathrm{V}_{5}\left(\mathrm{c}_{1}\right)_{\text {new }}-\Delta \mathrm{V}_{5}\left(\mathrm{c}_{1}\right)_{\text {ref }}=\mathrm{p}\left(\mathrm{c}_{1}\right)_{\text {new }} \cdot\left({ }^{\text {new }} \mathrm{V}_{5}-\left\langle\mathrm{V}_{5}\left(\mathrm{c}_{1}\right)\right\rangle \text { new }\right)-\mathrm{p}\left(\mathrm{c}_{1}\right)_{\text {ref }}\left({ }^{\mathrm{ref}} \mathrm{V}_{5}-\right. \\
& \left.\left\langle\mathrm{V}_{5}\left(\mathrm{c}_{1}\right)\right\rangle_{\text {ref }}\right) ;\left\langle\mathrm{V}_{5}\left(\mathrm{c}_{1}\right)\right\rangle=\text { average of MR for } \mathrm{c}_{1}\end{aligned}$ \\
\hline $\mathrm{b}_{8}$ & $\Delta \Delta \mathrm{V}_{6}\left(\mathrm{c}_{2}\right)$ & 0.0044 & $\mathrm{~V}_{6}=\log \mathrm{P}$ & $\begin{aligned}= & \Delta \mathrm{V}_{6}\left(\mathrm{c}_{2}\right)_{\text {new }}-\Delta \mathrm{V}_{6}\left(\mathrm{c}_{2}\right)_{\text {ref }}=\mathrm{p}\left(\mathrm{c}_{2}\right)_{\text {new }} \cdot\left({ }^{\text {new }} \mathrm{V}_{6}-\left\langle\mathrm{V}_{6}\left(\mathrm{c}_{2}\right)\right\rangle \text { new }\right)-\mathrm{p}\left(\mathrm{c}_{2}\right)_{\text {ref }}\left({ }^{\mathrm{ref}} \mathrm{V}_{6}-\right. \\
& \left.\left\langle\mathrm{V}_{6}\left(\mathrm{c}_{2}\right)\right\rangle_{\text {ref }}\right) ;\left\langle\mathrm{V}_{6}\left(\mathrm{c}_{2}\right)\right\rangle=\text { average of } \log \mathrm{P} \text { for } \mathrm{c}_{2}\end{aligned}$ \\
\hline $\mathrm{b}_{9}$ & $\Delta \Delta \mathrm{V}_{1}\left(\mathrm{c}_{4}\right)$ & -0.0037 & $\mathrm{~V}_{1}=\mathrm{Mw}$ & $\begin{aligned}= & \Delta \mathrm{V}_{1}\left(\mathrm{c}_{4}\right)_{\text {new }}-\Delta \mathrm{V}_{1}\left(\mathrm{c}_{4}\right)_{\text {ref }}=\mathrm{p}\left(\mathrm{c}_{2}\right)_{\text {new }} \cdot\left({ }^{\text {new }} \mathrm{V}_{1}-\left\langle\mathrm{V}_{1}\left(\mathrm{c}_{4}\right)\right\rangle \text { new }\right)-\mathrm{p}\left(\mathrm{c}_{2}\right)_{\text {ref }}\left({ }^{\mathrm{ref}} \mathrm{V}_{1}-\right. \\
& \left.\left\langle\mathrm{V}_{1}\left(\mathrm{c}_{4}\right)\right\rangle_{\text {ref }}\right) ;\left\langle\mathrm{V}_{1}\left(\mathrm{c}_{4}\right)\right\rangle=\text { average of Mw for } \mathrm{c}_{2}\end{aligned}$ \\
\hline $\mathrm{b}_{10}$ & $\Delta \Delta \mathrm{V}_{1}\left(\mathrm{c}_{5}\right)$ & -0.0036 & $\mathrm{~V}_{1}=\mathrm{Mw}$ & $\begin{aligned}= & \Delta \mathrm{V}_{1}\left(\mathrm{c}_{5}\right)_{\text {new }}-\Delta \mathrm{V}_{1}\left(\mathrm{c}_{5}\right)_{\text {ref }}=\mathrm{p}\left(\mathrm{c}_{5}\right)_{\text {new }} \cdot\left({ }^{\text {new }} \mathrm{V}_{1}-\left\langle\mathrm{V}_{1}\left(\mathrm{c}_{5}\right)\right\rangle \text { new }\right)-\mathrm{p}\left(\mathrm{c}_{5}\right)_{\text {ref }}\left({ }^{\mathrm{ref}} \mathrm{V}_{1}-\right. \\
& \left.\left\langle\mathrm{V}_{1}\left(\mathrm{c}_{5}\right)\right\rangle_{\text {ref }}\right) ;\left\langle\mathrm{V}_{1}\left(\mathrm{c}_{5}\right)\right\rangle=\text { average of } \mathrm{Mw} \text { for } \mathrm{c}_{5}\end{aligned}$ \\
\hline $\mathrm{b}_{11}$ & $\Delta \Delta \mathrm{V}_{4}\left(\mathrm{c}_{6}\right)$ & -0.1682 & $\mathrm{~V}_{4}=$ Aeigp & $\begin{aligned}= & \Delta \mathrm{V}_{4}\left(\mathrm{c}_{6}\right)_{\text {new }}-\Delta \mathrm{V}_{4}\left(\mathrm{c}_{6}\right)_{\text {ref }}=\mathrm{p}\left(\mathrm{c}_{6}\right)_{\text {new }} \cdot\left({ }^{\text {new }} \mathrm{V}_{4}-\left\langle\mathrm{V}_{4}\left(\mathrm{c}_{6}\right)\right\rangle \text { new }\right)-\mathrm{p}\left(\mathrm{c}_{6}\right)_{\text {ref }}\left({ }^{\mathrm{ref}} \mathrm{V}_{4}-\right. \\
& \left.\left\langle\mathrm{V}_{4}\left(\mathrm{c}_{6}\right)\right\rangle_{\text {ref }}\right) ;\left\langle\mathrm{V}_{4}\left(\mathrm{c}_{6}\right)\right\rangle=\text { average of Aeigp for } \mathrm{c}_{6}\end{aligned}$ \\
\hline $\mathrm{b}_{12}$ & $\left(\Delta \Delta \mathrm{V}_{6}\left(\mathrm{c}_{3}\right)\right)^{2}$ & 0.0182 & $\mathrm{~V}_{6}=\log \mathrm{P}$ & $\begin{array}{l}=\Delta \mathrm{V}_{6}\left(\mathrm{c}_{3}\right)_{\text {new }}-\Delta \mathrm{V}_{6}\left(\mathrm{c}_{3}\right)_{\text {ref }}=\mathrm{p}\left(\mathrm{c}_{3}\right)_{\text {new }} \cdot\left[{ }^{\text {new }} \mathrm{V}_{6}-\left\langle\mathrm{V}_{6}\left(\mathrm{c}_{3}\right)\right\rangle \text { new }\right)-\mathrm{p}\left(\mathrm{c}_{3}\right)_{\text {ref }}{ }^{\text {ref }} \mathrm{V}_{6} \\
\left.\left.-\left\langle\mathrm{V}_{6}\left(\mathrm{c}_{3}\right)\right\rangle_{\text {ref }}\right)\right]^{2} ;\left\langle\mathrm{V}_{6}\left(\mathrm{c}_{3}\right)\right\rangle=\text { average of } \log \mathrm{P} \text { for } \mathrm{c}_{3}\end{array}$ \\
\hline
\end{tabular}

${ }_{\mathrm{a}} \mathrm{f}\left(\varepsilon_{\mathrm{ij}}\right)_{\text {ref }}=\left\langle\varepsilon_{\mathrm{ij}}\right\rangle_{\text {ref }}=\langle\operatorname{IPA}(\%)\rangle$ ref average of reference entries for conditions of $\mathrm{c}_{1}=$ treatments, $\mathrm{c}_{2}=$ with $/$ without fermentation, $\mathrm{c}_{3}$ $=$ phase, $\mathrm{c}_{4}=$ gas chromatography protocol, $\mathrm{c}_{5}=$ replicates, and $\mathrm{c}_{6}=$ cis/trans pattern. ${ }_{\mathrm{b}}$ Symbols of molecular descriptors calculated using the DRAGON software: $\mathrm{V}_{1}=\mathrm{Mw}, \mathrm{V}_{2}=$ Aeigv, $\mathrm{V}_{3}=$ Aeige, $\mathrm{V}_{4}=$ Aeigp, $\mathrm{V}_{5}=A M R, \mathrm{~V}_{6}=\log \mathrm{P}$, and $\mathrm{V}_{7}=(\log \mathrm{P})^{2}$. The parameters $\Delta \mathrm{V}_{\mathrm{k}}\left(\mathrm{c}_{\mathrm{j}}\right)$ are moving averages, and $\Delta \Delta \mathrm{V}_{\mathrm{k}}\left(\mathrm{c}_{\mathrm{j}}\right)=\mathrm{p}\left(\mathrm{c}_{\mathrm{j}}\right)^{\text {new }} \cdot\left({ }^{\text {new }} \mathrm{V}_{\mathrm{k}}-\left\langle\mathrm{V}_{\mathrm{k}}\left(\mathrm{c}_{\mathrm{j}}\right)\right\rangle{ }^{\text {new }}\right)-\mathrm{p}\left(\mathrm{c}_{\mathrm{j}}\right)$ ref. $\left({ }^{\mathrm{ref}} \mathrm{V}_{\mathrm{k}}-\left\langle\mathrm{V}_{\mathrm{k}}\left(\mathrm{c}_{\mathrm{j}}\right)\right\rangle{ }^{\text {ref }}\right)$ are $\mathrm{PT}$ operators.

Table 8 Results of the LDA PT-LFER model for the perturbation network of fatty acid distribution in ruminal microbiome

\begin{tabular}{|c|c|c|c|c|}
\hline \multirow{2}{*}{ Data sub-set ${ }^{a}$} & \multirow{2}{*}{ Statistical parameter } & \multirow{2}{*}{ Prediction rates $(\%)$} & \multicolumn{2}{|c|}{ Prediction cases } \\
\hline & & & No. $\left(\mathrm{L}_{\mathrm{nr}}=0\right)$ & No. $\left(\mathrm{L}_{\mathrm{nr}}=1\right)$ \\
\hline \multicolumn{5}{|l|}{ Training dataset } \\
\hline No. $\left(\mathrm{L}_{\mathrm{nr}}=0\right)$ & Specificity & 82.9 & 127292 & 26275 \\
\hline No. $\left(\mathrm{L}_{\mathrm{nr}}=1\right)$ & Sensitivity & 91.1 & 13403 & 136742 \\
\hline Train total & Accuracy & 86.9 & $90.5 \%^{b}$ & $83.9 \%^{c}$ \\
\hline \multicolumn{5}{|l|}{ Validation dataset } \\
\hline No. $\left(\mathrm{L}_{\mathrm{nr}}=0\right)$ & Specificity & 81.7 & 40118 & 8986 \\
\hline No. $\left(\mathrm{L}_{\mathrm{nr}}=1\right)$ & Sensitivity & 84.9 & 8282 & 46557 \\
\hline Validation total & Accuracy & 83.4 & $82.9 \%^{b}$ & $83.8 \%^{c}$ \\
\hline
\end{tabular}

a Number in total $=407655$; No. $\left(\mathrm{L}_{\mathrm{nr}}=0\right)$ represents the number of cases in the sub-set with $\mathrm{L}_{\mathrm{nr}}=0$ (not connected nodes) or the same with new and reference states when IPA $(\%)_{\text {new }} \leq \operatorname{IPA}(\%)_{\text {ref. }}$ No. $\left(\mathrm{L}_{\mathrm{nr}}=1\right)$ represents the number of cases in the sub-set with $\mathrm{L}_{\mathrm{nr}}$ $=1$ (links in the network), or the same with new and reference states when IPA $(\%)_{\text {new }}>\operatorname{IPA}(\%)_{\text {ref }}$ b NPV: negative predictive value. c PPV: positive predictive value. 


\subsection{PT-NLFER model for a FA distribution network}

Additional tests have been conducted using STATISTICA, using linear and non-linear ANN (LNNs and MLPs) methods in order to compare them with the above LDA model. LNNs have one input layer and one output layer, but no hidden layer. Therefore, the predicted output is a linear combination of the input neuron values, similar to the LDA model. MLPs have at least one hidden layer of neurons. The ANNs have been used in the literature to find diverse classification models. ${ }^{66-68}$ Accordingly, and strictly speaking, the LNN models are also PT-LFER models because they are linear relationships. However, they are included in this section because they are a particular case of ANNs. In contrast, the MLP models can be classified as PT-NLFERs (PT-Non-Linear Free Energy Relationships), because they consider nonlinear relationships between the input PT operators and the output.

Table 9 presents the best 11 ANN models with the corresponding statistics for the best LDA classification. The MLP models have different input variables, from 5 to 12 and the LNN models are based on 8 to 12 variables. The results demonstrate the prediction power of the non-linear ANNs (MLPs) against the linear models (LDA and LNNs). The best MLP model (no. 6: MLP 12:12-11-1:1) has 12 input variables and only one hidden layer with 11 neurons. It can predict $93.73 \%$ of the test cases and it classifies $92.54 \%$ of the training cases. This model has around $10 \%$ more prediction power compared to the LDA PT-LFER model but only 5.6\% more classification power in training. The PT-NLFER model obtained with MLP number 6 classified our dataset better than the LDA PT-LFER model. However, PTLFER is notably simpler and shows a direct relationship between the input variables and the output. If the results are sorted by the test classification (validation preference), the order of the models is the following: MLPs-6, 5, 4, 3, 2, 1; 12 (LDA model); LNNs-9, 8, 10, 11, 7. Thus, the LDA model has a better prediction capacity than all LNNs but less than MLPs. Between MPLs, the models with only 5 input variables can be observed (compared with the 12 ones for LDA), but the LDA model classifies $4.70 \%$ more of the training set, even if the MLP one can predict $4.92 \%$ more of the test set. Another advantage of the LDA model is the low training and validation errors compared to all ANNs (around 25\% of the ANN errors). In conclusion, the MLP models were better problem solvers, but notably more complicated. 
Table 9 Comparative study of PT-LFER vs. PT-NLFER models ${ }^{a}$

\begin{tabular}{|c|c|c|c|c|c|}
\hline \multirow{2}{*}{ Model no. description } & \multirow{2}{*}{ Typical topology } & \multicolumn{4}{|c|}{ Statistical parameters ${ }^{b}$} \\
\hline & & $\mathrm{TP}(\%)$ & $\mathrm{VP}(\%)$ & TE $(\%)$ & $\operatorname{VE}(\%)$ \\
\hline \multicolumn{6}{|l|}{ PT-NLFER models } \\
\hline 1-MLP 12:12-13-1:1 & & 87.61 & 87.91 & 59.97 & 85.07 \\
\hline 2-MLP 5:5-10-1:1 & & 82.25 & 88.31 & 56.22 & 47.65 \\
\hline 3-MLP 6:6-8-1:1 & & 87.60 & 90.07 & 49.93 & 51.87 \\
\hline 4-MLP 7:7-10-1:1 & & 88.22 & 90.40 & 46.13 & 40.90 \\
\hline 5-MLP 12:12-10-1:1 & & 92.54 & 92.10 & 43.61 & 53.88 \\
\hline 6-MLP 12:12-11-1:1 & & 92.54 & 93.73 & 41.81 & 41.18 \\
\hline \multicolumn{6}{|l|}{ PT-LFER models } \\
\hline 7-LNN 8:8-1:1 & & 85.68 & 81.73 & 33.94 & 35.85 \\
\hline 8-LNN 9:9-1:1 & & 86.60 & 82.12 & 33.50 & 36.09 \\
\hline 9-LNN 10:10-1:1 & & 86.73 & 82.14 & 33.46 & 36.11 \\
\hline 10-LNN 11:11-1:1 & 8 & 86.63 & 82.00 & 33.45 & 36.16 \\
\hline 11-LNN 12:12-1:1 & & 86.62 & 81.98 & 33.43 & 36.23 \\
\hline 12-LDA 12:12-1:1 & & 86.94 & 83.39 & 15.03 & 19.92 \\
\hline
\end{tabular}

a PT-LFERs: Perturbation Theory-Linear Free Energy Relationships; PT-NLFERs: Perturbation Theory-Non-Linear Free Energy Relationships. $\mathrm{b}$ TP $(\%)=$ Training Performance, VP $(\%)=$ Validation Performance, TE $(\%)=$ Training Error, VE $(\%)=$ Validation Error.

The number of nodes $=$ fatty acids (sum of input results i) of the complex networks was 744 (the full details are presented in http://dx.doi.org/10.6084/m9.figshare.1408852). It can be concluded that the classification results, obtained using this new PT-LFER equation, are promising and confirm the potential of the present methodology. The present model is the result of combining Hansch analysis with LDA models, Box-Jenkins operators, and Perturbation Theory ideas. Our group and other authors ${ }^{69-74}$ have used LDA models alone or combined with Box-Jenkins operators to predict the properties of complex systems, ${ }^{75-78}$ and these models may include or not perturbation theory considerations. ${ }^{79}$ However, in this paper these ideas are extended to the Hansch analysis for the first time.

\subsection{Construction of a FA distribution network using the PT-LFER model}

Network biology ${ }^{80}$ is accepted as a very useful approach to shed light on the functional organization of the cell. With this idea in mind, the observed complex networks were built for perturbations in FA metabolism/distribution between ruminal media and bacterial or protozoan individuals. In so doing it was considered that two states are connected $\left(\mathrm{L}_{\mathrm{nr}}=1\right)$ if both $\mathrm{f}\left(\varepsilon_{\mathrm{ij}}\right)_{\text {new }}=\operatorname{IPA}(\%)_{\text {obs }}$ and $\mathrm{f}\left(\varepsilon_{\mathrm{ij}}\right)_{\mathrm{ref}}=\operatorname{IPA}(\%)_{\mathrm{obs}}-$ $\operatorname{IPA}(\%)_{\text {ref }}>0$, and $\mathrm{L}_{\mathrm{nr}}=0$ otherwise. This condition indicates that the level of both fatty acids in the new state is higher than that of fatty acids in the state of reference (initial state). Consequently, our network is a network of co-distribution of fatty acids. In addition, the model was used to predict the same complex network. To this end, it was considered that $\mathrm{L}_{\mathrm{nr}}=1$ (nodes linked) when both values of ' $\mathrm{f}\left(\varepsilon_{\mathrm{ij}}\right)_{\text {new }}$ and 
'f $\left(\varepsilon_{\mathrm{ij}}\right)_{\text {ref }}$ predicted by the model have the probability $\mathrm{p}\left(\mathrm{c}_{\mathrm{ij}}\right)>0.5$ of having $\mathrm{f}\left(\varepsilon_{\mathrm{ij}}\right)_{\text {ref }}=\operatorname{IPA}(\%)_{\mathrm{obs}}-\operatorname{IPA}(\%)_{\text {ref }}$ $>0$.

Last, two models of random networks (random networks 1 and 2) were also built (Table 10). Each model was defined with a number of nodes and links as similar as possible to the observed and predicted networks, respectively. The objective was to understand the overall nature of the FA metabolism/distribution data (similar to a random process or not). The average values of some topological indices were calculated to compare quantitatively the structure of these networks. The indices calculated were the average values of the vertex-vertex topological distance, ${ }^{50}$ node degree, and closeness of the giant component of the observed, predicted network models and the two similar random ones. ErdősRényi (ER) random networks were, apparently, similar to the observed and predicted networks. In fact, the average values of the topological distance, node degree, and closeness are similar, halfway between the observed and predicted network (1.83 vs. 1.77, 72.75 vs. 80.29, and 0.000755 vs. 0.000836, respectively).

Table 10 Giant components of the observed, predicted, and random networks

\begin{tabular}{|c|c|c|c|c|}
\hline Observed networks & Value & Average indices ${ }^{a}$ & Value & Predicted networks \\
\hline & 1.8 & Distance & 1.8 & \\
\hline & 72.7 & Degree & 80.3 & \\
\hline & 0.0008 & Closeness & 0.0008 & \\
\hline \multirow[t]{4}{*}{ ER random network ${ }^{b} 1$} & Value & Average indices & Value & ER random network 2 \\
\hline & 1.9 & Distance & 1.9 & \\
\hline & 68.6 & Degree & 80.0 & \\
\hline & 0.0007 & Closeness & 0.0008 & \\
\hline
\end{tabular}

a Distance means the average values of the vertex-vertex topological distance, degree and closeness mean the node degree, and closeness of the giant component, respectively. b ER random network means the Erdős-Rényi random network.

\section{Conclusions}

A mixed experimental-theoretical methodology can be used to study the effect of multiple factors over fatty acid distribution networks on ruminal microbiome. PT and LFER ideas can be combined to develop a PT-LFER model of fatty acid distribution networks. Box-Jenkins and PT operators of physicochemical parameters are useful inputs in this sense. ANN algorithms are also useful to test the performance of alternative PT-NLFER; non-linear models. Last, ER random network models can be employed to carry out comparative studies with the observed and predicted networks in order to study the overall effect of perturbations on the fatty acid distribution processes.

\section{Acknowledgements}

Yong Liu acknowledges the Mexican Council for Science and Technology (CONACyT), scholarship (2014-MZO2015) and student interchange (Ref. 290842), for financial support for doctoral research studies. The authors also thank CENID FyMA, INIFAP for providing experimental animals and laboratory for the analysis of the fatty acid compositions. This work was supported by the "Galician Network for Colorectal Cancer Research (REGICC)" (Ref. R2014/039), funded by the Xunta de Galicia, by "Collaborative Project on Medical Informatics (CIMED)" PI13/00280, funded by the Carlos III Health Institute from the Spanish National plan for Scientific and Technical Research and Innovation 20132016, and the European Regional Development Funds (FEDER). The authors acknowledge support from the Galician Network of Drugs R + D REGID (Xunta de Galicia R2014/025). 


\section{References}

1. A. P. Simopoulos, Biomed. Pharmacother., 2002, 56, 365-379.

2. A. P. Simopoulos, Exp. Biol. Med., 2008, 233, 674-688.

3. A. P. Simopoulos, Biomed. Pharmacother., 2006, 60, 502-507.

4. A. P. Simopoulos, Am. J. Clin. Nutr., 1999, 70, 560s-569s.

5. S. Kwak, S. Myung, Y. Lee, H. Seo and f. Korean Meta-analysis Study Group, Arch. Intern. Med., 2012, 172, 686-694.

6. G. C. Burdge and P. C. Calder, Nutr. Res. Rev., 2006, 19, $26-52$.

7. H. C. Bucher, P. Hengstler, C. Schindler and G. Meier, Am. J. Med., 2002, 112, 298-304.

8. E. C. Rizos, E. E. Ntzani, E. Bika, M. S. Kostapanos and M. S. Elisaf, J. Am. Med. Assoc., 2012, 308, 10241033.

9. S. L. Kronberg, E. J. Scholljegerdes, G. Barcelo-Coblijn and E. J. Murphy, Lipids, 2007, 42, 1105-1111.

10. H. V. Petit, J. Dairy Sci., 2002, 85, 1482-1490.

11. T. M. Hess, J. K. Rexford, D. K. Hansen, M. Harris, N. Schauermann, T. Ross, T. E. Engle, K. G. Allen and C. M. Mulligan, J. Anim. Sci., 2012, 90, 3023-3031.

12. K. i. Ichihara and Y. Fukubayashi, J. Lipid Res., 2010, 51, 635-640.

13. J. G. Kramer, V. Fellner, M. R. Dugan, F. Sauer, M. Mossoba and M. Yurawecz, Lipids, 1997, 32, 1219-1228.

14. M. M. Or-Rashid, N. E. Odongo and B. W. McBride, J. Anim. Sci., 2007, 85, 1228-1234.

15. A. Varnek and I. I. Baskin, Mol. Inf., 2011, 30, 20-32.

16. C. Hansch, A. R. Steward and J. Iwasa, Mol. Pharmacol., 1965, 1, 87-92.

17. K. C. Chou and Y. D. Cai, J. Chem. Inf. Model., 2005, 45, 407-413.

18. E. Estrada, E. Uriarte, E. Molina, Y. Simon-Manso and G. W. Milne, J. Chem. Inf. Model., 2006, 46, 2709-2724.

19. B. Ehresmann, M. J. de Groot and T. Clark, J. Chem. Inf. Model., 2005, 45, 1053-1060.

20. I. V. Tetko and G. I. Poda, J. Med. Chem., 2004, 47, 5601-5604.

21. I. V. Tetko, V. Y. Tanchuk, T. N. Kasheva and A. E. Villa, J. Chem. Inf. Comput. Sci., 2001, 41, 246-252.

22. K. Roy and J. T. Leonard, J. Chem. Inf. Model., 2005, 45, 1352-1368.

23. E. E. Anslyn and D. A. Dougherty, Modern Physical Organic Chemistry, University Science Books, 2006.

24. J. W. Gibbs, A Method of Geometrical Representation of the Thermodynamic Properties of Substances by Means of Surfaces, The Academy, 1871.

25. W. Greiner, D. Rischke, L. Neise and H. Stöcker, Thermodynamics and Statistical Mechanics, Springer, New York, 2000.

26. C. Hansch, D. Hoekman, A. Leo, D. Weininger and C. D. Selassie, Chem. Rev., 2002, 102, $783-812$.

27. C. Hansch, A. Kurup, R. Garg and H. Gao, Chem. Rev., 2001, 101, 619-672.

28. C. Hansch, W. E. Steinmetz, A. J. Leo, S. B. Mekapati, A. Kurup and D. Hoekman, J. Chem. Inf. Comput. Sci., 2003, 43, 120-125.

29. H. Gonzalez-Diaz, S. Arrasate, A. Gomez-SanJuan, N. Sotomayor, E. Lete, L. Besada-Porto and J. M. Ruso, Curr. Top. Med. Chem., 2013, 13, 1713-1741.

30. G. Calviello, H. M. Su, K. H. Weylandt, E. Fasano, S. Serini and A. Cittadini, BioMed Res. Int., 2013, 2013, 743171.

31. P. C. Calder, C. Glaser, M. Klingler, B. Koletzko, N. D. Riediger, S. Serini, I. Innocenti, E. Piccioni and G. Calviello, Vitamins in the Prevention of Human Diseases, 2011, pp. 629-696.

32. Nutrient Requirements of Small Ruminants: Sheep, Goats, Cervids, and New World Camelids, The National Academies Press, Washington, DC, 2007.

33. S. X. Tang, G. O. Tayo, Z. L. Tan, Z. H. Sun, L. X. Shen, C. S. Zhou, W. J. Xiao, G. P. Ren, X. F. Han and S. B. Shen, J. Anim. Sci., 2008, 86, 1164-1172.

34. K. H. Menke and H. Steingass, Animal Research and Development, 1988, 28, 7-55.

35. F. Legay-Carmier and D. Bauchart, Br. J. Nutr., 1989, 61, 725-740.

36. S. Na, Analysis of Fatty Acids in Infant Formulas Using an Agilent J\&W HP-88 Capillary GC Column, Agilent Technologies (China) Co. Ltd., 2011.

37. J. Folch, M. Lees and G. H. Sloane Stanley, J. Biol. Chem., 1957, 226, 497-509.

38. T. Hill and P. Lewicki, STATISTICS Methods and Applications. A Comprehensive Reference for Science, Industry and Data Mining, StatSoft, Tulsa, 2006.

39. H. Hong, Q. Xie, W. Ge, F. Qian, H. Fang, L. Shi, Z. Su, R. Perkins and W. Tong, J. Chem. Inf. Model., 2008, $48,1337-1344$.

40. H. Gonzalez-Diaz, L. G. Perez-Montoto and F. M. Ubeira, J. Immunol. Res., 2014, 2014, 768515.

41. A. M. Helguera, R. D. Combes, M. Pérez González and M. N. D. S. Cordeiro, Curr. Top. Med. Chem., 2008, 8, $1628-1655$.

42. E. Papa, F. Villa and P. Gramatica, J. Chem. Inf. Model., 2005, 45, 1256-1266.

43. A. Mauri, V. Consonni, M. Pavan and R. Todeschini, MATCH, 2006, 56, 237-248.

44. A. A. Toropov and E. Benfenati, Curr. Drug Discovery Technol., 2007, 4, 77-116.

45. A. Karwath and L. De Raedt, J. Chem. Inf. Model., 2006, 46, 2432-2444.

46. M. A. Siani, D. Weininger and J. M. Blaney, J. Chem. Inf. Comput. Sci., 1994, 34, 588-593.

47. D. Vidal, M. Thormann and M. Pons, J. Chem. Inf. Model., 2005, 45, 386-393.

48. S. Haykin, Neural Networks: A Comprehensive Foundation, Prentice Hall PTR, 1998.

49. B. Junker, D. Koschutzki and F. Schreiber, BMC Bioinf., 2006, 7, 219. 
50. M. E. Newman, S. H. Strogatz and D. J. Watts, Phys. Rev. E: Stat., Nonlinear, Soft Matter Phys., 2001, 64, 026118.

51. J. Salimon, T. A. Omar and N. Salih, Sci. World J., 2014, 2014, 10.

52. P. C. Calder, Am. J. Clin. Nutr., 2006, 83, 1505S-1519S.

53. P. C. Calder, Prostaglandins, Leukotrienes Essent. Fatty Acids, 2006, 75, 197-202.

54. P. C. Calder, Mol. Nutr. Food Res., 2008, 52, 885-897.

55. P. C. Calder, Br. J. Clin. Pharmacol., 2013, 75, 645-662.

56. A. Cittadini, G. Calviello, H. M. Su and K. Weylandt, BioMed Res. Int., 2013, 2013, 905986.

57. I. S. Nam and P. C. Garnsworthy, J. Appl. Microbiol., 2007, 103, 551-556.

58. P. F. Wilde and R. M. Dawson, Biochem. J., 1966, 98, 469-475.

59. P. Kankaanpää, B. Yang, H. Kallio, E. Isolauri and S. Salminen, Appl. Environ. Microbiol., 2004, 70, 129-136.

60. H. Goldfine, J. Lipid Res., 1984, 25, 1501-1507.

61. D. C. Bay and R. J. Turner, Biochim. Biophys. Acta, Biomembr., 2013, 1828, 260-270.

62. P. A. Janmey and P. K. Kinnunen, Trends Cell Biol., 2006, 16, 538-546.

63. A. Lock and D. Bauman, Lipids, 2004, 39, 1197-1206.

64. M. J. Allison, M. P. Bryant, I. Katz and M. Keeney, J. Bacteriol., 1962, 83, 1084-1093.

65. P. Fontanille, V. Kumar, G. Christophe, R. Nouaille and C. Larroche, Bioresour. Technol., 2012, 114, 443-449.

66. H. González-Díaz, D. M. Herrera-Ibatá, A. Duardo-Sánchez, C. R. Munteanu, R. A. Orbegozo-Medina and A. Pazos, J. Chem. Inf. Model., 2014, 54, 744-755.

67. A. Duardo-Sánchez, C. R. Munteanu, P. Riera-Fernández, A. López-Díaz, A. Pazos and H. González-Díaz, J. Chem. Inf. Model., 2013, 54, 16-29.

68. H. González-Díaz, F. Prado-Prado, E. Sobarzo-Sánchez, M. Haddad, S. Maurel Chevalley, A. Valentin, J. Quetin-Leclercq, M. A. Dea-Ayuela, M. Teresa Gomez-Muños, C. R. Munteanu, J. José Torres-Labandeira, X. García-Mera, R. A. Tapia and F. M. Ubeira, J. Theor. Biol., 2011, 276, 229-249.

69. A. Duardo-Sanchez, C. R. Munteanu, P. Riera-Fernandez, A. Lopez-Diaz, A. Pazos and H. Gonzalez-Diaz, J. Chem. Inf. Model., 2014, 54, 16-29.

70. H. Gonzalez-Diaz, D. M. Herrera-Ibata, A. Duardo-Sanchez, C. R. Munteanu, R. A. Orbegozo-Medina and A. Pazos, J. Chem. Inf. Model., 2014, 54, 744-755.

71. N. Alonso, O. Caamano, F. J. Romero-Duran, F. Luan, D. S. C. MN, M. Yanez, H. Gonzalez-Diaz and X. GarciaMera, ACS Chem. Neurosci., 2013, 4, 1393-1403.

72. H. Gonzalez-Diaz and P. Riera-Fernandez, J. Chem. Inf. Model., 2012, 52, 3331-3340.

73. G. Aguero-Chapin, A. Antunes, F. M. Ubeira, K. C. Chou and H. Gonzalez-Diaz, J. Chem. Inf. Model., 2008, 48, 2265-2277.

74. G. Aguero-Chapin, H. Gonzalez-Diaz, G. de la Riva, E. Rodriguez, A. Sanchez-Rodriguez, G. Podda and R. I. Vazquez-Padron, J. Chem. Inf. Model., 2008, 48, 434-448.

75. A. Speck-Planche, V. V. Kleandrova, F. Luan and M. N. Cordeiro, Eur. J. Pharm. Sci., 2012, 47, $273-279$.

76. A. Speck-Planche, V. V. Kleandrova, F. Luan and M. N. Cordeiro, Anti-Cancer Agents Med. Chem., 2013, 13, 791-800.

77. A. Speck-Planche, V. V. Kleandrova and M. N. Cordeiro, Eur. J. Pharm. Sci., 2013, 48, 812-818.

78. A. Speck-Planche, V. V. Kleandrova, F. Luan and M. N. Cordeiro, Curr. Alzheimer Res., 2013, 10, 117-124.

79. H. Gonzalez-Diaz, S. Arrasate, A. Gomez-San Juan, N. Sotomayor, E. Lete, L. Besada-Porto and J. M. Ruso, Curr. Top. Med. Chem., 2013, 13, 1713-1741.

80. A. L. Barabasi and Z. N. Oltvai, Nat. Rev. Genet., 2004, 5, 101-113. 